UNIVERSITÉ DU QUEBEC

MÉMOIRE PRÉSENTÉ À

L'UNIVERSITÉ DU QUÉBEC À CHICOUTIMI

COMME EXIGENCE PARTIELLE DE LA MAITRISE EN ART

Par

NADIA BERTRAND

HUMANISER L'UNIVERSITÉ PAR UNE EXPÉRIENCE ARTISTIQUE 


\section{Bibliothèque}

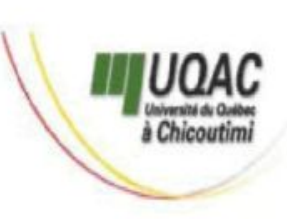

\section{Mise en garde/Advice}

Afin de rendre accessible au plus Motivated by a desire to make the grand nombre le résultat des results of its graduate students' travaux de recherche menés par ses research accessible to all, and in étudiants gradués et dans l'esprit des accordance with the rules règles qui régissent le dépôt et la governing the acceptation and diffusion des mémoires et thèses diffusion of dissertations and produits dans cette Institution, theses in this Institution, the I'Université du Québec à Université du Québec à Chicoutimi (UQAC) est fière de Chicoutimi (UQAC) is proud to rendre accessible une version make a complete version of this complète et gratuite de cette œuvre. work available at no cost to the reader.

L'auteur conserve néanmoins la The author retains ownership of the propriété du droit d'auteur qui copyright of this dissertation or protège ce mémoire ou cette thèse. thesis. Neither the dissertation or Ni le mémoire ou la thèse ni des thesis, nor substantial extracts from extraits substantiels de ceux-ci ne it, may be printed or otherwise peuvent être imprimés ou autrement reproduced without the author's reproduits sans son autorisation. permission. 


\section{Sommaire}

En créant des expériences esthétiques basées sur l'échange entre les êtres humains, je tente de stimuler et d'élargir la mise en contact du langage artistique avec les gens qui fréquentent le milieu universitaire. Mes œuvres se basent sur l'urgence que je ressens de développer une attitude de mise en disponibilité et d'ouverture à l'autre afin d'établir un dialogue. Ma démarche artistique se rallie à l'art premier : l'art de vivre.

Je veux créer des moments privilégiés de contacts humains dans des espaces publics, moments qui deviennent une mise en révélation de soi et de l'autre dans une interrelation. Je concentre ainsi mes activités artistiques sur le développement de la mise en contact de l'autre avec moi. L'œuvre consiste donc à organiser des moments qui offrent une temporalité, un rythme différent de ce que l'on vit normalement dans le quotidien, et de construire ce temps avec une autre personne. Un rythme propice pour s'ouvrir à ce que l'espace, le lieu et l'entourage ont à nous offrir pour ainsi se mettre en disponibilité à ce qui

est. À l'intérieur d'un lieu fréquenté de tous, se recrée une réalité qui nous met davantage en liaison avec nos sens. Les sens du corps comme on les connaît, soit la vue, le toucher, l'odorat et l'ouie, mais également la mise en contact avec des sens intérieurs comme l'émotivité et la sensibilité.

Je travaille à partir de déclencheurs, ces gestes inattendus qui ont pour fonctions de fragmenter les actions, de nous remettre en contact avec le monde. L'ensemble de ces expériences a intensifié ma fascination pour les comportements humains. Cet intérêt pour l'interaction humaine m'amène à élaborer des stratégies interactionnelles qui viseront à 
tracer un portrait d'un microcosme humain et à retoumer, tel un reflet de miroir, ce portrait à ceux qui le constituent. Par contre, ces cuvres, ces interventions me conduisent à me poser plusieurs questions de nature éthique : si les expériences que je propose s'insèrent dans un processus de création artistique pour laquelle l'artiste et l'autre deviennent une forme de matériau, à qui appartient l'cuvre, et où s'arrête mon droit de manipuler ce matériau?

Tout ou long de ma recherche, qui se voulait une mise en disposition des gens d'un certain milieu en rapport avec leur entourage, soit leur environnement et la population, je me suis confrontée à différents questionnements, dont celui de déterminer ce que sera l'œuvre finale. À mon sens, l'œuvre produite n'est jamais finale, elle est une étape, menant à une autre qui elle, à son tour, mènera à une autre et ainsi de suite. Dans le cadre de ma maîtrise, il m'a été très difficile de mettre terme et je crois que mon travail de recherche continue, seulement le lieu d'exploration change. 


\section{Remerciements}

Je tiens à remercier ma directrice Élisabeth Kaine qui, engagée dans sa recherche, a toujours pris le temps de lire et de relire cet essai. J'apprécie son attention clairvoyante ainsi que son appui. Ces deux années de recherche m'ont permis d'être stable géographiquement et d'approfondir mes connaissances. Mon sac garni d'outils, je prépare mon envol sur la continuité de mes pistes de réflexions ainsi que sur l'exploration de nouveaux territoires.

Je voudrais également souligner la naissance de nouvelles amitiés sincères qui m'ont appuyée. Je pense en autre à Julie Alain, Michèle Bouchard, Marie-Ève Émond, Françoyse Lamontagne et Sylvie Poisson qui m'ont écoutée, encouragée et parfois mis des mots sur les sentiments abstraits qui m'habitaient. Ainsi, je pouvais mieux voir et comprendre mon cheminement artistique. Je pense également à mon ami Michel, luthier, qui me fait vivre des expériences où le rapport temps/vitesse prend de nouvelles dimensions. Et bien entendu ma mère, Liette Bertrand, la femme que j'aime le plus au monde, une relation en perpétuelle évolution, là où la rationnalité et le sentiment se rencontrent... 


\section{TABLE DES MATIÈRES}

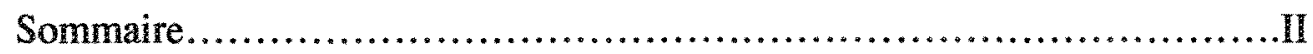

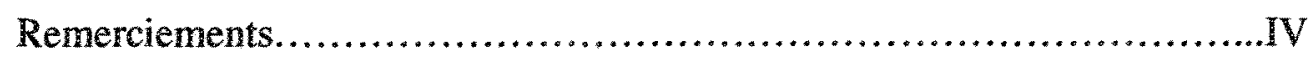

Table des matières.....................................................

Table des illustrations..................................................

Introduction..........................................................

Chapitre 1 Genèse, positionnement et définition du sujet..........11

Chapitre 2 Problématique.........................................19

Chapitre 3 Les premières expériences............................23

Chapitre 4 Bilan................................................. 30

Chapitre 5 Phae finale........................................41

Conclusion......................................................43

Annexe A(annotation sonore) $\ldots \ldots \ldots \ldots \ldots \ldots \ldots \ldots \ldots \ldots \ldots \ldots . .53$

Les inspirations............................................54

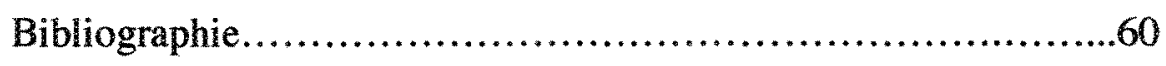

Lectures stimulatives........................................62 


\section{TABLE DES ILLUSTRATIONS}

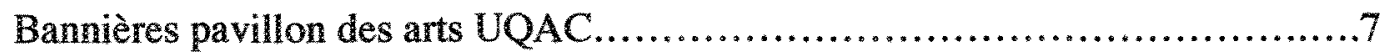

Mains poème confiance et espoir Hutte de l'amour, fév. 2002...................33

Mains poème l'amour envers les autres et oser et assumer, Hutte de l'amour, fév. 2002..........34

Mains poème empathie, Hutte de l'amour, fév. 2002 ............................35

Illustration A $360^{\circ}$

Milenka et Le philosophe, $360^{\circ}$, Toronto 2001 ..............................48

Angela et Jonny, $360^{\circ}$, Toronto 2001 .....................................49

Illustration $\mathrm{B}$

Consultation et Couture du bouton, Doctor Strange Love, octobre $2002 \quad$.....50

Illustration $\mathrm{C}$

Rita, collaboratrice et Etape 2 du rituel, Hutte de l'amour, fév 2002 ............51

Christophe et Installation phase finale, collaborateur, Hutte de l'amour .........52

Annexe A

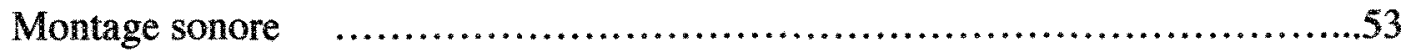

Les inspirations

À Toutes Celles qui ont retrouvées leur dignité..................................54

Culture du monde ..........................................................55

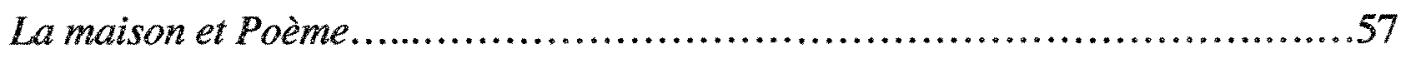

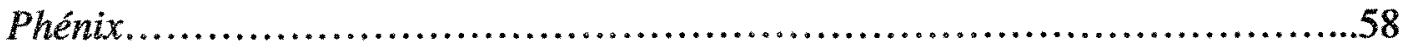

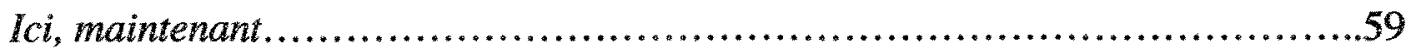




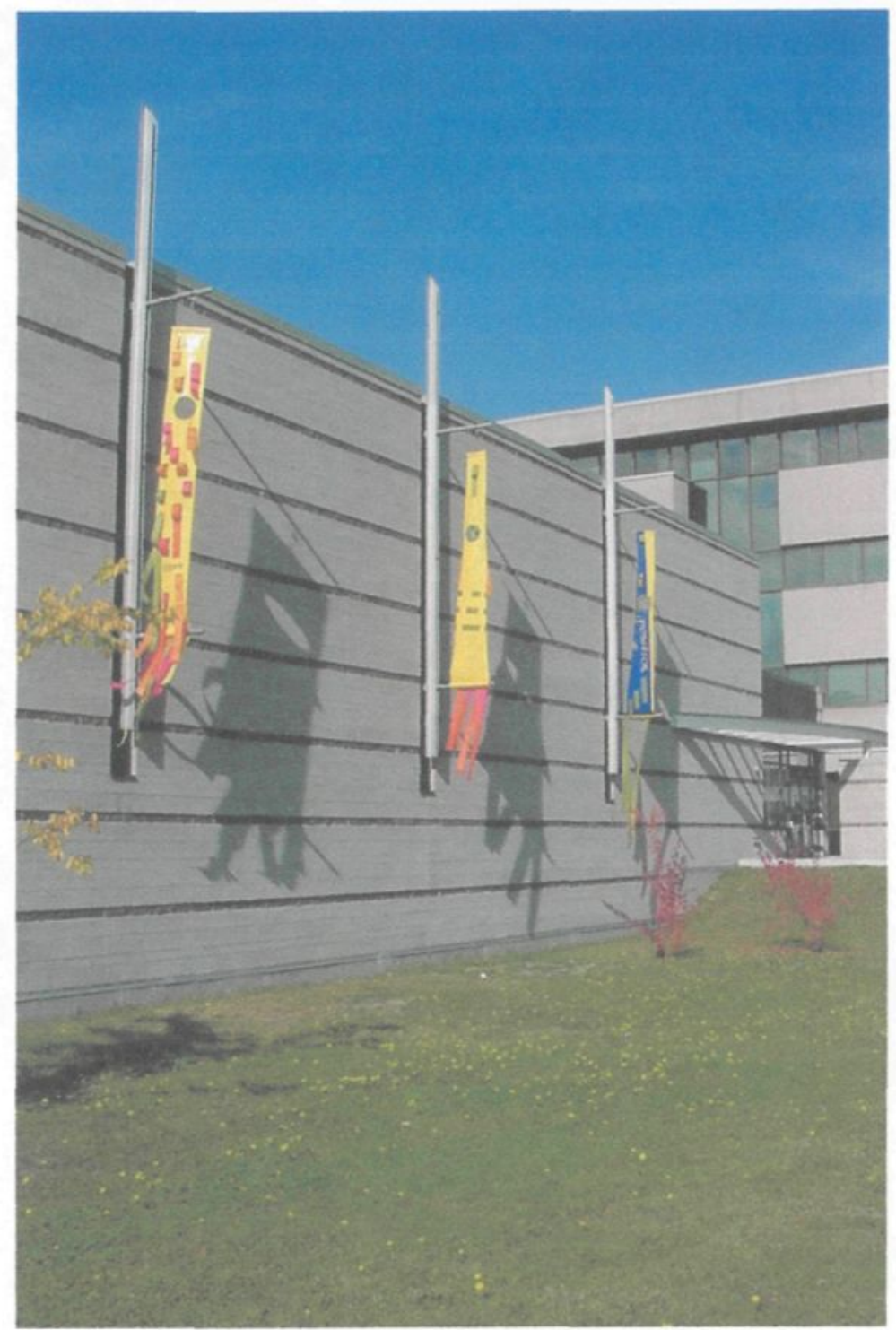

Bannières créées dans le cadre de la rentrée septembre 2004 


\section{Introduction}

Notre quotidien est rempli de stimuli auditifs ou visuels auxquels nous choisissons d'accorder ou non notre attention. Dans le cadre de la rentrée 2004 , j'ai conçu des bannières accrochées au Pavillon des Arts. Hier, assise sur la pelouse de l'université, je regardais une tondeuse motorisée passer sur le chemin, tout en me demandant si le conducteur du tracteur avait remarqué les bannières. Lors de mon séjour au Saguenay, j’ai voulu stimuler et élargir la mise en contact du langage artistique avec les gens qui fréquentent le milieu universitaire, ef cela en créant des expériences esthétiques basées sur l'échange entre les êtres humains. Mes cuvres se basent sur l'urgence que je ressens de développer une attitude de mise en disponibilité, d'ouverture à l'autre pour établir un dialogue.

Par cette nouvelle étape de ma recherche artistique et personnelle, je veux apprendre à me connaître en élargissant mes champs de connaissance, développer une confiance en ce que je fais afin d'explorer des zones hors limites, rendre conscience de mon existence et de celle du monde à travers mes interactions avec les gens et mon milieu et construire des lieux qui deviennent des dispositifs de communication entre les humains. Ces lieux que j'installe dans la trame sociale ont d'ailleurs pour fonction essentielle de permettre la mise en contact par un procédé utile à la réflexion et à la perception de soi. 
Un autre de mes objectifs est d'ouvrir (par la mise en contact avec une forme d'art relationnel) le champ des arts à la population universitaire. L'implication dans l'œuvre, l'engagement et l'investissement personnel sont en fait primordiaux pour « comprendre» l'art. Lorsque j'utilise le mot « comprendre », je fais référence à ce sentiment qui rejoint les gens en tant qu'êtres humains. Ma stratégie est de rendre une forme d'art contemporain plus accessible en amenant les personnes à être disponibles à cette forme d'art, c'est-à-dire en état de réceptivité. Je veux élaborer une ceuvre qui puise à même le réel et qui rend compte des gens qui seront en contact avec elle. Une oeuvre qui invite le passant à devenir participant dans l'œuvre, pendant et après l'élaboration, soit une ouvre en continu.

\section{La quête du bonheur}

Je vous ferai part dans cet essai de réflexions, issues de mon cheminement de projet de maîtrise, en misant sur l'importance du contexte de réalisation ainsi que sur l'intégration des stratégies de mise en situation de l'action artistique. Une démarche qui demande un temps d'arrêt afin d'arriver à se donner un espace intérieur pour vivre et pour ressentir des émotions émergeant lors de la mise en contact et de la création de l'œuvre.

Dans un premier temps, je ferai une description de mes interventions artistiques, en lien avec mes préoccupations humanistes. Suivra une tentative visant à situer ma pratique artistique dans une continuité historique de l'expression artistique. Je développerai par la suite une problématique qui situe mon travail au sein de questions plus larges, en lien avec ce que nous sommes et avec les lieux que nous fréquentons; de là l'importance du lieu qu'investit l'artiste en rapport avec l'acte de création, ainsi que l'inscription des liens qu'il instaure avec ce lieu. Pour mon projet de mâtrise, *ce lieu est' l'Université du Québec à 
Chicoutimi. Puis, je présenterai les traces de l'œuvre réalisée : un récit fragmentaire d'un portrait social. Enfin, je vous ferai part de l'étape finale qui se déroule également à I'UQAC. Une œuvre qui prend forme de parcours in situ suggérée par une trame sonore inspirée de rencontres. En conclusion, je ferai un résumé de mes réflexions en regard des différentes étapes de mon projet: la rencontre, l'expérience, le suivi du portrait interprétatif, l'exposition et la redistribution, les répercussions des réalisations, les satisfactions, les insatisfactions et les nouvelles pistes de réflexion. 


\section{Chapitre 1}

\section{Genèse}

\section{La glaneuse funambule}

«Parce que tout équilibre commence par sa propre syntonie. Être en accord avec soi-même pour vivre en harmonie avec son environnement. »

Eugène Mulle, viticulteur

Fascinée par les textures, la couleur et surtout la magie de l'expression, j'ai depuis longtemps cueilli ce que mon environnement immédiat avait à offrir, et j'ai façonné cette matière à ma façon. À l'école primaire, je récupérais les retailles de papier de construction que les élèves mettaient à la corbeille, élargissant ainsi l'éventail de couleurs disponibles à mon imagination. La création et mon environnement ont toujours été étroitement liés. À l'époque de ma petite enfance, j'ai abondamment joué avec la matière. L'adolescence me conduisit à explorer un nouveau terrain de jeu tandis que je commençais à m'intéresser à l'être humain et à ses comportements comme manifestations expressives. Probablement à cause des nombreuses heures passées dans l'autobus en direction de l'école secondaire, confinée à un banc, $\mathrm{j}$ 'ai commencé à observer les comportements humains dans les lieux publics.

\footnotetext{
'Eugène Mulle, viticulteur et auteur du roman autobiographique Ma Vigne, Ma Vie, 1997
} 
«Hey! T'es assis à ma place?»

Eric Villeneuve, étudiant quatrième secondaire ${ }^{2}$

\section{Le rituel du quotidien L'art après l'école}

Au moment où, un peu ampoulée, je complétais un baccalauréat en arts visuels, je me suis retrouvée quelque peu désabusée de l'art en contexte institutionnel. L'enseignement des arts était alors très axé sur les techniques. Ma curiosité pour l'art comme forme d'expression étant grandissante, j'ai commencé à me questionner sur l'essence de l'art comme moyen de communication. Mes doutes éveillèrent une remise en question sur la convenance ou plutôt la pertinence de l'enseignement des arts en milieu universitaire. En terminant mon baccalauréat, je fus animée d'une aspiration qui m'appela à expérimenter les réalités de la vie autrement qu'à travers le statut d'étudiante.

J'entrepris donc un voyage d'exploration en Amérique du Nord. Il est important de dire que j'utilisais l'auto-stop comme moyen de transport. La nuit, je logeais chez des amis ou chez des étrangers en fonction de ma situation géographique. Les gens qui m'accueillaient me racontaient leur vie, leurs peurs, leurs rêves. Siéger dans la voiture ou le camion de quelqu'un, ou encore dormir sous son toit, prédisposait la relation au respect et à la confiance, ce qui automatiquement créait une complicité. Ces gens de tous âges, aux différentes professions et préoccupations, manifestaient une ouverture et un intérêt pour les êtres humains, ce qui facilitait l'échange. Vivre chez les gens une nuitée, une semaine, m'a permis d'élargir mon idée sur ce que sont les valeurs des américains du nord et de me construire un portrait autre que celui proposé par la télévision.

\footnotetext{
${ }^{2}$ Commentaire entendu de vive voix en 1989 à Si-Bruno de Montarville
} 
Cette façon de conduire mon existence me ramena à une chose très importante dans ma démarche artistique : l'art premier, l'art de vivre que Pierre Bertrand, philosophe contemporain, définit comme suit : «L'art le plus subtil, le plus vivant, est celui qui passe inaperçu, qui ne laisse de trace. L'art d'être, de percevoir, de sentir, d'entrer en relation avec ce qui est. » (Bertrand, 2001 p.43)

\section{Divinité À VENDRE}

\section{Positionnement et définition du sujet}

Si on se rapporte aux premières manifestations artistiques de l'histoire, celles-ci faisaient intégralement partie de la vie quotidienne sous forme de rituels ou de fabrication d'objets utilitaires. L'histoire de l'art met ces objets en scène à travers les écrits et la muséologie, et constitue ainsi un portrait à partir duquel nous voyons la relation de l'art à la société se transformer, se diviser. À l'origine des manifestations artistiques, l'objet créé était en lien avec les divinités par la représentation de personnages ou de symboles; l'art avait ainsi des fonctions sacrées. Au début du $19^{\circ}$ siècle Hegel enseignait que :

«La plus haute destination de l'art est celle qui lui est commune avec la religion et la philosophie. Comme celles-ci, il est un mode d'expression du divin, des besoins et des exigences les plus élevés de l'esprit (...) Les peuples ont déposé dans l'art leurs idées les plus hautes, et il constitue souvent pour nous le seul moyen de comprendre la religion d'un peuple. L'art diffère de la religion et de la philosophie par le fait qu'il possède le pouvoir de donner de ces idées élevées une représentation sensible qui nous les rend accessibles. ${ }^{3}$

\footnotetext{
${ }^{3}$ Hegel, G.W.F (1993), Esthétique des Arts Plastiques, des sciences et des arts, Paris, 332 p.
} 
Nietzsche ${ }^{4}$, philosophe du XIXe siècle, remettant l'existence de Dieu ${ }^{5}$ en question, poussa les artistes à trouver refuge dans la matérialité, explorant la matière pour la matière même. Je pense ici aux cubistes qui décomposèrent la forme des gens ou des objets pour offrir une multitude de points de vue d'une même chose; le point de vue unique (absolu) n'existait plus. Tandis qu'Einstein', physicien, nous démontrait la théorie de la relativité, les modernes firent de la peinture non plus en nous offrant différentes facettes de l'objet, mais en proposant la peinture qui traite de peinture. André Malraux ${ }^{7}(1926)$, littéraire et homme politique, dira que l'homme devient avec la modernité, le seul objet digne de nous passionner. Ainsi, l'individualisme donnant la place que dieu avait à l'homme. L'art moderne tendra jusqu'à l'absurde cette quête de soi-même. Marcel Duchamp ${ }^{8}$, artiste et fervent joueur d'échec, poussera à l'extrême la définition de l'art en disant que son plus grand art est ce qu'il fait de son temps. Il utilisait des objets manufacturés qu'il mettait en scène, ces cuvres se nomment ready-made. Par simple désignation, un objet industrialisé devenait objet d'art.

${ }^{4}$ Friedrich Nietzsche( 1844-1900), philosophe allemand « Il affirme en outre que l'Etre n'est pas « tout- fait » : il n'est ni Dieu, ni Vérité établie, mais Devenir et, donc, (comme la Vie) création coujours renouvlée incessante fuite vers un « autre chose » en quoi il se dépasse constamment soimême. (Dictionnaire Hachette 1988)

${ }^{5}$ Dieu « L'être suprème, créateur et conservateur de l'Univers, adoré dans divers religions monothéistes. (Dictionnaire Hachette 1998)

${ }^{6}$ Albert Einstein (1879-1955), physicien et mathématicien. « Il a édifié une théorie générale de l'Univers, la relativité, qui s'est inposée pour expliquer de nombreux phénomènes obsevés à l'échelle atomique et astronomique. $\#$ (Dictionnaire Hachette 1988)

${ }^{7}$ André Malraux (1901-1976), écrivain et homme politique « homme d'action il a participé aux luttes et aux aventures du monde contemporain » (Todd, Olivier, André Malraux Une Vie, 2001) ${ }^{8}$ Marcel Duchamp (1887-1968), artiste français naturalisé américain « En 1913, sa Roue de bicyclette sur tabouret illustre sa notion du ready-made (objet tout fait), estimant que choisir un objet signifie déjà créer une œuvre d'art \# ( L'art au 20e siècle, 2000) 
Le postmodernisme serait l'éclatement des formes d'expression, tout serait art ou ayant le potentiel d'être de l'art (libération par l'irrationnel). Me considérant comme une artiste, j'adhère à la vision de l'art qui serait plutôt une vision de l'artiste non pas comme un créateur, mais comme « celui qui ressent ». Cette sensibilité serait mise à la disposition des autres pour faire naître en nous l'infinie diversité du monde.

\section{Définition du sujet}

Je veux créer des moments privilégiés de contacts humains dans des espaces publics, moments qui deviennent une mise en révélation de soi et de l'autre dans une interrelation. Au départ, dans les expérimentations artistiques que je déployais, ce qui m'importait était l'action, celle de provoquer des situations de mise en relation entre l'autre et moi au sein desquelles j'incarnais un élément déclencheur. Cette façon d'entrer en contact, d'interpeller l'autre directement, m'a souvent donné le sentiment positif de réussir à créer un moyen de communication efficace sans en retenir de traces. Les manœuvres ou les actions que je considère comme faisant partie de ma démarche artistique étaient généralement peu ou pas documentées. Cet art tricoté étroitement à la vie intime des gens prescrivait, selon moi, une certaine retenue à prendre une photo ou à filmer; photographier l'expérience gênait et perturbait son déroulement. Une grande majorité de gens ont une aversion profonde à se faire prendre en photo, ce qui provoque souvent un réflexe de crispation générant une pose statique. Ce réflexe comportemental entravait mon objectif de vouloir créer un moment fluide.

À cette réticence de capter les traces des expériences s'ajoutèrent deux pertes majeures qui remirent en cause mes valeurs profondes de la vie : l'une matérielle et l'autre 
humaine. Ces événements m'ont amenée à considérer les relations humaines, les contacts et les moments avec les gens comme étant ce qu'il y a de plus important dans la vie. Ce qui relayair toutes traces matérielles, telles photos, vidéos et œuvres d'art matérielles, au rang de détails futiles. Je concentrais alors mes activités artistiques sur la mise en contact de l'autre avec moi. J'associais l'idée de conserver une trace tangible de ces expériences aux concepts de posséder, de montrer et de se montrer, toutes des notions qui ne suscitaient pas mon attention.

C'est seulement quelques années plus tard, suite à la curiosité et à l'intérêt que suscitait mon travail pour mon entourage, que j'ai commencé tranquillement à penser à documenter certaines expériences. J'ai donc développé une stratégie de documentation intégrée au processus. J'accorde depuis une grande importance à l'intégration de ce moment de captation à l'oeuvre, afin de permettre de documenter ce moment sans le figer. Ainsi, pour la présente recherche à la maîtrise, une part importante de mon aftention s'est portée sur cette problématique.

En tant qu'artiste, je veux rafraîchir l'élément de la pensée ( constitué à mon sens par la tête) ainsi que réchauffer le muscle du cœur (qui représente à mon sens ce sentiment) en traçant des chemins qui relient les deux. Enclencher un fonctionnement autonome qui relie ces deux zones pour une meilleure communication. Mettre les gens en contact avec une vision de l'art comme moyen de communication qui transforme la pensée tramée à même le quotidien. J'aspire à créer « une cuvre qui fonctionne comme un dispositif relationnel comportant un certain degré d'aléatoire, une machine à provoquer et à gérer des rencontres individuelles ou collectives. » (Bourriaud, 2001 p.32). 
Par mon sujet de recherche, je tente de stimuler et d'élargir la mise en contact du langage artistique avec les gens qui fréquentent le milieu universitaire en créant des expériences esthétiques basées sur l'échange entre les êtres humains. Mes œuvres se basent sur l'urgence que je ressens de développer une attitude de mise en disponibilité, et d'ouverture à l'autre pour établir un dialogue.

L'ensemble de ces expériences a intensifié ma fascination pour les comportements humains. Cet intérêt pour l'interaction humaine m'emmène donc, dans le cadre d'études de deuxième cycle en art, à élaborer des stratégies interactionnelles qui viseront à tracer un portrait d'un microcosme humain, et à retourner, tel un reflet de miroir, ce portrait à ceux qui le constituent. L'œuvre mâ̂tresse qui passe par un processus relationnel représente un portrait, une interprétation de ce qu'est le monde, des gens qui habitent et qui occupent un lieu. Un aperçu qui passe par une expérience à travers les sens où ceux-ci sont mis en éveil et suivi d'une matérialisation de la rencontre par la création d'une œuvre trace.

L'œuvre consiste à organiser des moments qui offrent une temporalité, un rythme différent de ce que l'on vit normalement dans le quotidien et de construire ce temps avec une autre personne. Un rythme propice à s'ouvrir à ce que l'espace, le lieu et l'entourage ont à nous offrir pour ainsi se mettre en disponibilité à ce qui est. Susciter un moment de communion, de prise de conscience, de mise en relation. Suite à quoi on crée, une oeuvre qui deviendra la trace de ce moment, un aide-mémoire qui se veut une empreinte dans la matière, une continuité de ce que l'on vit ensemble à un moment précis. Révélér en couleurs, en formes ou en sons ce qui se trame à l'intérieur de notre cour et de notre cerveau, mais aussi à l'intérieur de notre corps social. 
En regardant les photos ou les ceuvres issues des expériences, j'ai réalisé l'importance des expressions qu'évoquent ces traces. Je m'intéresse depuis sérieusement à ces dernières qui deviennent le reflet de ce que nous formons comme groupe. Les portraits individuels générés par ces expériences offrent diverses expressions. Unir ces éléments hétérogènes les uns aux autres constitue une forme qui va donner naissance aux diverses particularités individuelles. C'est à partir de ce moment que mon travail artistique se construit en deux axes parallèles en symbiose : une œuvre de création qui fait vivre une expérience à l'intérieur d'un monde imaginaire se construisant à même le réel en créant un espace propice à l'effleurement; et une cuvre de transmission constituée des traces captées lors de l'expérience. Ces traces contiennent un échantillonnage des gens qui ont contribué à faire de cette récolte une œuvre, devenant en quelque sorte un «singulier » portrait anthropologique. Il s'agit de deux axes, une même œuvre, une œuvre en phases multiples. 


\section{Chapitre 2}

\section{Problématique}

\section{L'apprivoisement et la confiance dans la différence}

«Qui sommes-nous? »

Amold Gauthier, garagiste

Un adage arabe avance qu'on se découvre autant de personnalités que le nombre de langues que l'on parle. Par certaines de mes observations et expériences de vie, j'avancerais que l'on a autant de potentialité de perceptivité que de gens que l'on côtoie. L'autre, dans nos fréquentations, devient une fenêtre, une perception du monde où l'on cohabite.

Par mes ceuvres, j'investis le réel, le quotidien du grand public. Je veux offrir une expérience différente aux passants, créant ainsi une possibilité d'intensité qui éveille les sens à la découverte de soi et de l'autre. J'agis dans mon environnement immédiat en apportant un interstice à la routine des gens. De nos jours, avec l'engouement pour la télévision et la technologie, le spectateur est de plus en plus passif. L'art que je propose se veut un processus de mise en relation qui active et qui relie ce que l'on a de différent en

\footnotetext{
${ }^{9}$ Arnold Gauthier, garagiste et auteur du roman autobiographique Le Tuyau, 1996
} 
tant qu'individu. Cet art uni les différences, par un rassemblement d'éléments hétérogènes, tout en laissant à chacun leur qualité propre.

Michel Maffessoli ${ }^{10}$, sociologue, a axé ses recherches sur cette question de la force de l'expérience esthétique comme unificatrice. Ce nouveau paradigme émergeant qu'il dénomme le paradigme esthétique, décrit bien le rôle de l'art au sein de l'expérience esthétique. Le fait de s'impliquer dans un échange crée un canal de communications à même le quotidien. On néglige souvent l'importance de la présence de l'autre qui s'organise en interrelation avec notre propre présence. L'idée d'intégrer l'art au quotidien des gens permet de construire notre propre façon de vivre ensemble, tout en prenant conscience des différences qui nous caractérisent comme individu. Par cette expérience commune, nous pouvons nous réconcilier avec cette différence, et ainsi harmoniser ce que nous sommes à nos comportements sociaux. ${ }^{11}$

\section{Surpasser la peur}

L'engouement pour la vitesse du «toujours plus, toujours plus vite» tend à l'uniformisation de la masse. Les technologies de pointe facilitent la fabrication en série, tandis que les moules sociaux, supportés par les institutions où l'on enseigne cette correspondance aux règles, ont des codes bien précis. La modernité, avec ses promesses de loisirs, a pris des allures d'esclavagisme; donnant naissance, par toutes sortes de stratégies pernicieuses, à d'avides consommateurs. La science et ses découvertes nous dévoilent un monde organisé dans l'infiniment petit, les molécules, les quarts, les neutrons. Une science qui va plus vite que l'éthique. On ne sait trop quoi faire et surtout jusqu'où aller avec les

\footnotetext{
${ }^{10}$ Concept développé dans son ouvrage : Aux creux des apparences

${ }^{11}$ Thème développé par différents auteurs : Pierre Bertrand, philosophe, et Nicolas Bourriaud, sociologue.
} 
questionnements qu'apportent les manipulations génétiques. Une science qui nous laisse démunis devant les grandes questions de l'essence de l'être humain. Ce vide soulève notre propre vulnérabilité, tout insécure que nous sommes dans l'infini du cosmos. La spécialisation de la main-d'oeuvre et des connaissances qu'a engendrée la technologie a eu comme effet de fragmenter le monde. Une séparation dans laquelle l'homme devient robot exécutant d'un système. Quoique l'on puisse observer et prédire des phénomènes physiques, chimiques ou biologiques, les scientifiques ne peuvent avec certitude donner «sens » à ce qu'est véritablement la vie.

Les penseurs du XIXe et du XXe siècles remirent nombre de nos perceptions occidentales en question, en autre l'existence d'une religion monothéiste, supposant un dieu créateur. Ce qui transposa les codes rigides de la pratique de la religion catholique au polythéisme. Les nouvelles divinités prennent la forme de multinationales assoiffées de sacrifices humains, tout en instaurant un système économique incompatible avec le développement durable. Le siècle du «prendre et jeter » n'opère pas de discernement : papier-mouchoir ou humain, les deux vont dans la même corbeille après utilisation. La seule vision globale offerte est celle des chiffres, le profit, le bénéfice net, les cotes à la bourse. L'Humain face à cette hécatombe se tourne, désespéré, vers des solutions chimiques telles les anti-dépresseurs, mais le nombre de gens souffrant de dépression est de plus en plus élévé et la tendance ne semble pas vouloir s'inverser.

« La seule façon d'exister pour la conscience est d'avoir conscience d'exister »

$$
\text { Jean-Paul Sartre }{ }^{i 2}
$$

\footnotetext{
${ }^{12} J e a n-P a u l$ Sartre, écrivain, philosophe qui vécut de 1905 à 1980 , citation tiré de l'ouvrage $L$ 'Être et le Néant (1943)
} 


\section{À mon échelle, comment puis-je répondre à cette problématique?}

Mes actions consistent à investir les lieux communs, ces endroits anodins où l'on ne se serait pas attardé en temps normal, puis je crée dans ce lieu les dispositions propices à provoquer quelque chose. Mon art vise à créer des conditions favorables à l'effleurement de l'intime dans des lieux publics. Je considère l'art comme étant une expérience touchante (dans le sens tactile et émotif du terme).

Par la mise en forme d'un rituel ou d'un simple geste, le corps devient révélant d'un état psychologique qui vise à exprimer une idée, nous conduisant ainsi à réfléchir sur notre propre façon d'agir. Le rituel, proposé par le façonnement d'une série de gestes, fait émerger un sens spécifique à chacun. À l'intérieur d'un lieu fréquenté de tous, il se recrée une réalité qui nous met davantage en connexion avec nos sens; les sens du corps comme on les connait, soit le toucher, l'odorat ou l'ouie, mais également la mise en contact avec des sens intérieurs comme l'émotivité, la sensibilité. 


\section{Chapitre 3}

\section{Les premières expériences}

\section{Artiste en résidence}

«L'œil choisit souvent de voir ce qu'il reconnaît »

$$
\text { Merce Cunningham }{ }^{13} \text {, chorégraphe }
$$

Lors du projet $360^{\circ}$, je me promenais avec une sculpture, une sphère de verre emplie de « cheerios » peints doré. J'accostais les piétons dans les rues de Toronto en leur demandant de tenir l'objet dans leur bras, ensuite je prenais une photo d'eux avec la sculpture. Ce projet proposait une interaction par l'entremise d'un objet. L'aspect ludique de la sculpture établissait une relation spontanée, éphémère à caractère convivial; l'objet avait également un rôle de mise en scène, et facilitait la captation d'un portrait dynamique de la personne que je photographiais. La façon avec laquelle chaque personne tenait l'objet et le regardait reflétait, à mon sens, un trait de personnalité. Les rencontres étaient en général très brèves.

Par la suite, avec Iso 140202, un projet inspiré par le jour de la St-Valentin, je pris une nouvelle tangente, et c'est à ce moment que j'ai commencé à impliquer d'autres personnes à la conception et à la participation des projets. Ce projet comptait trois volets

\footnotetext{
${ }^{13}$ HARRIS, Mélissa ,(1997) Merce Cunningham, un demi siècle de danse, Paris, Plume
} 
soit, dans un premier temps, la fabrication de cartes de souhaits; dans un deuxième temps une rencontre avec des élèves du secondaire qui inscrivaient à l'intérieur de ces cartes des petits mots d'encouragement. Finalement, dans un troisième temps, j'offrais ces cartes aux passants dans la ville de Montréal le soir de la St-Valentin.

L'automne suivant, je fis un retour à l'université dans le cadre d'une mâtrise en art. Une de mes premières interventions a eu lieu à l'Halloween : Dr Strange Love, ce titre est inspiré d'un personnage de film de Stanley Kubrick ${ }^{14}$. Invitée à une fête dans un appartement d'étudiants à Chicoutimi où je ne connaissais que quelques personnes, je portais une chemise de laboratoire et siégeais dans une chaise roulante, et $j$ 'ai alors profité de cette occasion pour initier sur le terrain une action artistique qui allait lancer une série d'expériences artistiques à caractère social. Je demandais à ces gens s'ils ressentaient une douleur à un endroit sur leur corps, et $j$ 'y fixais un bouton à l'aide de fil et d'aiguille. La soirée se continua au centre social de l'UQAC où j'ai manoeuvré à dépister d'autres maux, ou zones sensibles, pour y coudre des boutons.

En février, j'ai retravaillé l'idée thématique de la St-Valentin avec le projet La Hutte de l'Amour, une cabane installée dans les escaliers du centre social de l'université qui invitait les passants à venir vivre une expérience humaine à l'intérieur. Ce projet s'étalait sur plusieurs jours, soit à l'occasion de la semaine de la St-Valentin qui chapeautait également la semaine de prévention du suicide. La hutte, une structure de bois recouverte de tissu, offrait un lieu intime d'arrêt, de rencontre et de recueillement au milieu d'un endroit très passant: les escaliers du centre social. Cette intervention se différencie des précédentes dans son approche, car contrairement à mon habitude d'aller vers l'autre, je

\footnotetext{
${ }^{14}$ Stanley Kubrick (1928-1999), cinéaste américain :Dr Strangelove (1964)
} 
laissais plutôt le passant faire lui-même le pas vers l'expérience. La hutte demandait que l'on retire ses chaussures et que l'on se cambre acrobatiquement pour y pénétrer. Le simple acte d'y entrer sans trop savoir ce qui se passait à l'intérieur demandait une prédisposition, une ouverture de la part du participant, et je crois que cette prédisposition est fondamentale à l'cuvre, Dès lors, lorsque les gens ont cette ouverture, l'expérience ne peut être qu'investie.

À l'intérieur de la hutte, un collaborateur attendait le visiteur. Les collaborateurs choisis étaient des gens intéressés par le projet, et avec lesquels je me suis associée pour que l'expérience puisse s'étendre sur plusieurs jours. Cette formule donna la chance aux gens de participer activement à l'cuvre. Une fois le passant aventuré dans la hutte, l'hôte déjà à l'intérieur procédait à un mini rituel, que j'avais élaboré, pour initier l'expérience humaine de partage.

Les recommendations en rapport au déroulement de l'œuvre.

\section{Les Étapes}

1-Acceuillir la personne, l'inviter à s'asseoir

2- La mettre en confiance, l'inviter à mettre les mains dans une substance poudreuse

3-Essuyer les mains à l'aide du plumeau

4-Déposer les mains de la personne sur la feuille

5-Demander à la personne de faire une forme de coeur en joignant ses deux mains

6-Tracer le contour des mains et par le fait même le coeur

7-Demander d'inscrire à l'intérieur ce qui est important pour la personne

8- Prendre une photo des mains en cour

9-Initier une discussion sur le sujêt (selon la disponibilité et le désir)

10-Metter fin à l'expérience quand vous sentez le moment opportun

Au revoir, Merci ! 


\section{Panser l'agitation}

Ces différentes étapes s'apparentant à un rituel avaient pour but de mettre le visiteur en contact avec ses sens, à commencer par le sens du toucher; le toucher, ce sens très sollicité à toutes heures de la journée. Dans tous nos déplacements, nos pieds foulent le sol; de même, toutes les manipulations d'objets engendrent le toucher, en général par les mains. Par contre, ce n'est pas parce qu'on en appelle aux sens que l'on a automatiquement une perception sur ses sensations. « La perception est plutôt du côté de la conscience; la sensation, du côté du corps : elle fournit la matière que la perception mettra en forme. » (Compte-Sponville, 2001). Mais à la vitesse folle où nous accomplissons nos actions, ce passage sensations-conscience ne s'opère peut-être qu'à demi! Les gestes rituels ont pour fonctions, en fragmentant les actions, de nous remettre en contact avec le monde puisque « les gestes qui constituent les rites ne sont pas vains, mais servent à tonifier les consciences. Les rites (...) recentrent l'attention sur le proche, la proximité, le domestique comme instances de base de toute société. » (Dukheim, 1987)

\section{Ressentir dans le sentir}

La substance poudreuse à toucher à l'étape \#2 était constituée d'un mélange de paillettes brillantes et de moulée (nourriture à lapin). Par cette étape, j'aspirais à solliciter le sens du toucher, ainsi que celui de la vue, créant l'émerveillement tout en instaurant un lieu mnémonique à l'imaginaire enfantin par l'idée du trésor. Cette étape d'introduction était très importante. Initiant un mouvement de la mise en contact par la sensation en rapport au corps et au monde, vers la perception du ressenti : le sentiment, le rapport à soi. L'hôte, à l'aide du plumeau, essuyait ensuite les mains pour enlever les résidus de poudre. Ce geste 
symbolique suggérait le moment du lien à autrui en mettant en contact les deux personnes par un don : prendre soin de l'autre, un geste symbolique puissant qui ramène au plaisir de l'enfance où notre mère nous lavait les mains. J'ai choisi d'utiliser les plumes pour leur douceur, j'étais consciente que l'utilisation du contact direct « main à main » aurait été trop compromettant pour les hôtes et, surtout, difficile à réaliser, car de nos jours toucher quelqu'un est souvent interprété comme étant à connotation sexuelle. Nous étions déjà très rapprochés de l'autre dans l'espace restreint de la hutte, ajouter le toucher peau à peau n'aurait pas étể pertinent.

Mon intention, contrairement à certaines performances qui prennent en otage, se voulait une expérience agréable et libre. Donc, le plumeau offrait un contact indirect peu compromettant, mais rappelant toutefois le bienfait du don de l'autre vers soi. Lorsque l'hôte traçait le ccur formé par les mains du visiteur sur une feuille, encore une fois il y avait contact par un objet: le crayon frôlait le contour de la main lors du tracé. Ensuite, on demandait à la personne d'inscrire à l'intérieur de ce tracé ce qui était important pour elle. L'idée étant qu'une fois la personne mise en contact avec ses émotions, le climat créé permettait une plongée à l'intérieur de soi. Dans le tourbillon de la vie étudiante, la frénésie de l'université, le temps soudainement s'arrêtait pour les deux personnes. L'agitation calmée, le participant prenait le temps de se demander : « qu'est-ce qui est important pour moi, dans la vie?». Les réponses ont été très variées, de l'amour, son chat, l'équilibre, les enfants et la confiance. Bref, toutes sortes de réponses jaillirent.

Je crois que ce projet, à sa modeste échelle, a permis, comme le formule Maffessoli, (1992) « (...) par un rythme spécifique, d'humaniser le temps inhumain des cadences imposées et l'ennui programme, et de se réapproprier, à l'insu du regard 
surplombant, des moments de son existence, et par là sauvegarder un équilibre physique et psychologique sans cela gravement menacé ». p56

Les collaborateurs, qui ont joué le rôle d'hôtes au cours des trois jours que durait l'expérience, étaient tous étudiants, certains en travail social, d'autres en psychologie ou en soins infirmiers. Ces étudiants furent très emballés par le projet et généreux dans leurs

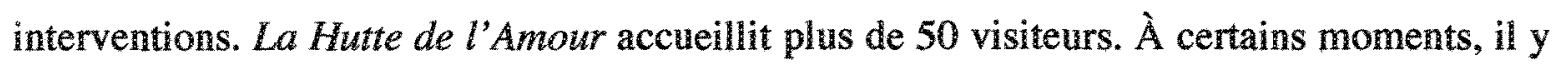
a même eu une file d'attente pour entrer dans la hutte. Le troisième jour, le jour de la fermeture, il y avait encore beaucoup de gens qui voulaient vivre l'expérience, La glace était brisée, la hutte apprivoisée, le bouche-à-oreille avait fonctionné. Cela m'indiqua que dans la prochaine expérience, il serait bien d'étendre sur plusieurs jours, voire une semaine complète, l'expérience. Les photos prises dans la hutte sont tout à fait fascinantes, car chaque paire de mains dévoile un état de la personne, la forme des mains en tant que telle ainsi que leur disposition sont signifiantes d'un état d'être. Avec les mots à l'intérieur, cet ensemble devient un poème dans la main.

C'est en regardant l'échantillonnage de ces photos que j'ai soudainement vu un portrait social des gens qui fréquentent l'université. Il a été important pour moi et pour ceux qui ont participé, d'exposer ces traces dans le but de redonner à la vue l'ensemble de ce portrait pour ceux qui ont participé à l'expérience ainsi que pour la «communauté » universitaire. La galerie, pour moi, n'offrait pas un milieu propice, car les gens qui ont participé à l'événement ne sont pas nécessairement ceux qui fréquentent les galeries. C'est pourquoi j'ai décidé d'exposer les traces de l'expérience dans le lieu même où elle avait eu 
cours. L'emplacement où a eu lieu l'expérience première est à mon avis le milieu le plus propice pour présenter, sous une autre forme, les témoignages récoltés lors de l'échange.

Je considère ce travail comme étant un travail d'équipe qui s'approche de ce qu'on appelle en anthropologie actuelle «la recherche collaborative», caractérisée par une relation d'échanges et de complémentarité chercheurs/participants. Ceux-ci sont associés dans la recherche d'un même but. J'aspire d'ailleurs à pratiquer ce mode de recherche dans mes expérimentations artistiques futures.

Or, une expérience qui a été pensée pour l'échange n'aurait pas eu une aussi grande participation dans une galerie, fréquentée, il ne faut pas s'en cacher, par une minorité de gens. De plus, en général, le public averti des galeries est très critique face à ces projets au caractère humain qui chevauchent intervention sociale et art. Si j'avais exposé ces traces en galerie, j'aurais eu l'impression d'utiliser les gens, de les trahir, de les «montrer». Un peu comme des animaux de zoo ou des rats de laboratoire, la galerie devenait la cage institutionnelle. Par contre, au centre social de l'université, le contact avec le public est immédiat et accessible, ce qui me satisfaisait comme lieu de redistribution. 


\section{Chapitre 4}

\section{Bilan sur ma méthode}

\section{Aller vers l'autre comme chemin vers soi.}

«Toute chose intimement ressentie peut se métamorphoser en symbole d'une situation universelle. » Tapies (1974)

Au départ, mes expériences étaient très dirigées. J'abordais les gens directement, les impliquant automatiquement à l'expérience comme dans $360^{\circ}$, Iso 140202 ou Dr Strange Love, tandis que la Hutte de l'Amour, elle, laissait plus de marges de mancuvres aux passants en les laissant participer sur une base volontaire à l'expérience. Une fois entrés dans la hutte, les gens étaient pris en charge. Les dernières expériences faites dans la cadre de ma maîtrise tentent d'éliminer le plus possible les systèmes de contrôle dans le processus de création de l'oeuvre. Je laisse l'autre venir à l'expérience, et nous construisons ensemble cette expérience. Je veux moi-même m'abandonner, être surprise à travers cet échange. Je désire susciter de l'autonomie chez le participant et non les prendre en charge. Il y a donc une transformation dans mon approche. 


\section{Stratégie et atmosphère}

La première étape de création de l'œuvre est la mise en place d'un dispositif qui devient la plate-forme de l'action de mise en présence, installation ou rendez-vous. L'installation est une mise en scène (espace fictif) dans un espace réel public, en l'occurrence l'Université du Québec à Chicoutimi. Par cette appropriation ludique de notre paysage familier, je propose une expérience dans le quotidien des passants en les surprenant, en les déstabilisant, proposant un rythme différent de celui déjà existant dans ce lieu. Par exemple La Hutte de l'Amour apportait un temps d'arrêt dans un lieu de passage. Ce projet invitait tous les passants, laissant ainsi plus de place au libre désir de participation que mes expériences précédentes.

Après avoir procédé au choix d'un lieu et d'un projet, il est primordial de me familiariser avec ce lieu en prenant contact avec l'architecture et les gens qui donnent vie à cet espace. Tout en apprivoisant l'environnement, en observant et en rencontrant les gens, je tisse à même ce lieu un réseau de contacts qui éventuellement sera sollicité lors de la mise en branle du projet et de la réalisation de l'expérience qui, rappelons le, tente d'initier une rencontre intime dans un lieu public.

Ce lieu symbolique qui donne naissance à l'oeuvre devient par la suite le lieu symbolisant. Le symbole est matérialisé par une trace commémorative exposée dans le lieu où se réalise l'expérience. J'utilise l'installation, la fabrication d'objets, la photographie, la vidéo, la danse, l'art du geste, l'art action, l'art interaction. Toutes ces disciplines sont possiblement confondues, repensées et réorganisées afin d'atteindre le but, à savoir la communication. L'utilisation et la combinaison de divers médiums me permettent de rejoindre un plus grand éventail de participants. La matière première est l'être humain : ses 
caractéristiques, ses comportements lorsqu'il est en interaction avec les autres. Je fais place à une communication qui, de prime abord, paraît parfois superficielle à cause des choix esthétiques qui mettent en forme l'expérience. Les installations, dans un passé très coloré, comportaient nombre d'éléments kitsch : le satin, le velours ainsi que l'utilisation d'objets «clichés » tels le cour, les ballons et les plumes, qui représentaient pour moi les nouveaux objets totémiques. J'exploite des lieux communs (au sens propre, des lieux où tout le monde passe. Au début j'ai utilisé des formes archétypales, elles aussi lieux communs. Dans cette exubérance « kitscheste », j'évoquais l'idée du bonheur en voulant désamorcer la peur du ridicule, et ainsi faciliter le dévoilement. Le dévollement se fait dans la façon d'agir, de réagir à l'action proposée; je veux faire place à un comportement qui habite le passant, mais qu'il n'ose révéler que dans certains lieux ou situations où il se sent en confiance. Lors de mes installations « loufoques », $\mathrm{j}$ aspirais à faire jaillir le côté ludique que nous avons tous; tandis que dans mes nouvelles approches, je laisse place à d'autres formes de révélation.

Lors de leur participation aux expériences, certaines réactions de passants ont été captées sur vidéo. Les mains de chaque participant de la Hutte de l'Amour ont été photographiées. Les portraits individuels pris au cours de l'expérience dégagent une variêté d'émotions étonnante, ce qui me conduit à confirmer la potentialité du portrait aux multiples facettes d'êtres humains ayant participé à une même expérience. Les portraits que je fais reflètent la personnalité sensible de chacun. Par exemple, les photographies captées dans le projet de La Hutte de l'Amour révèlent un état intérieur de la personne: la disposition des mains, les blessures, le mot choisì à l'intérieur, deviennent un langage exprimé dans la posture qu'il est possible de décoder ou du moins de ressentir. 


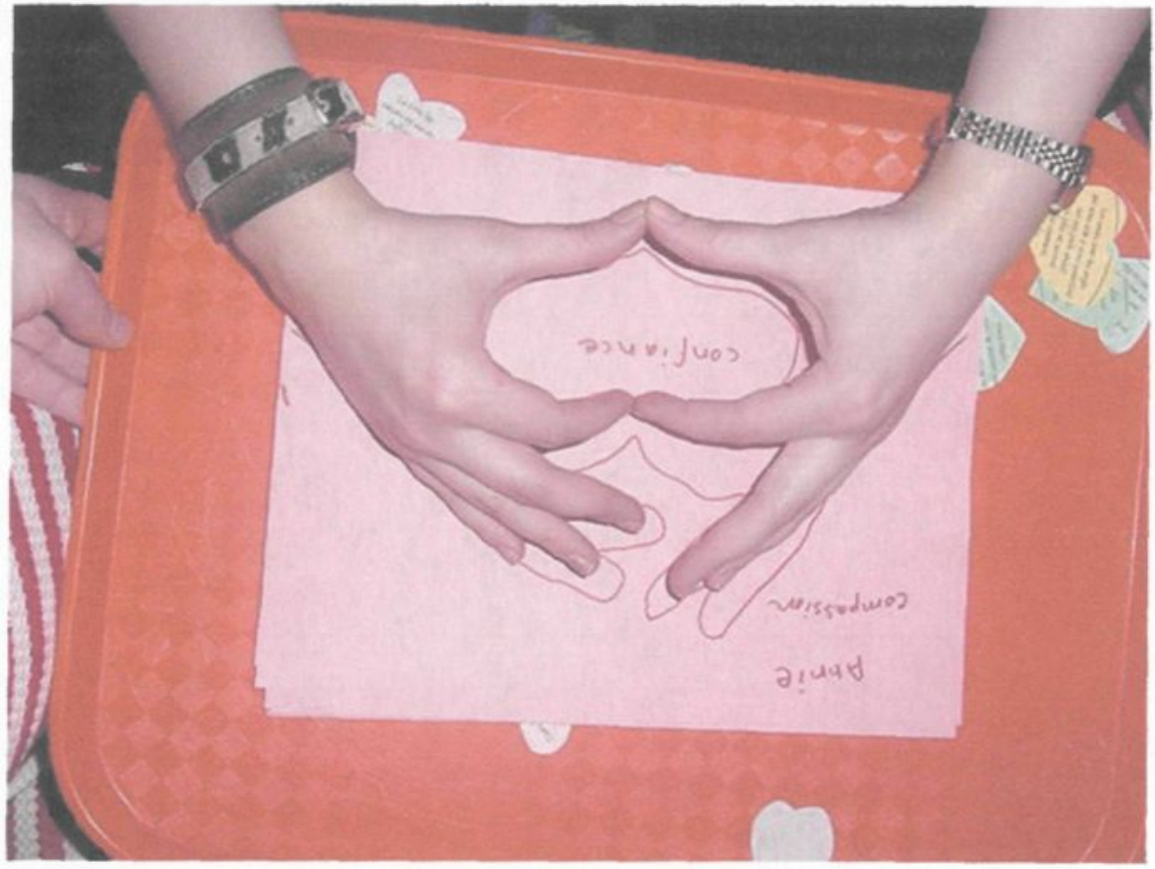

Mains poème confiance, Hutte de l'amour, fév. 2002

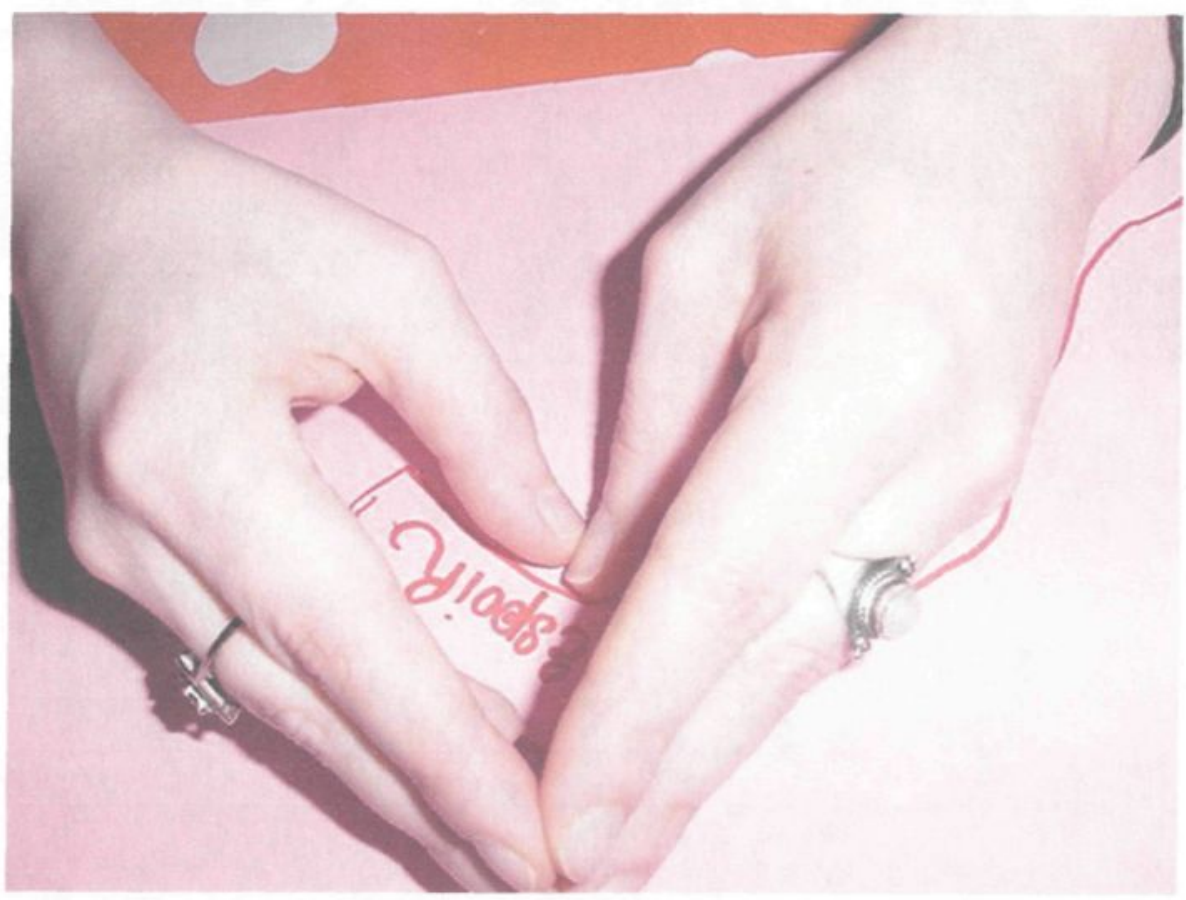

Mains poème espoir, Hutte de l'amour, fév. 2002 


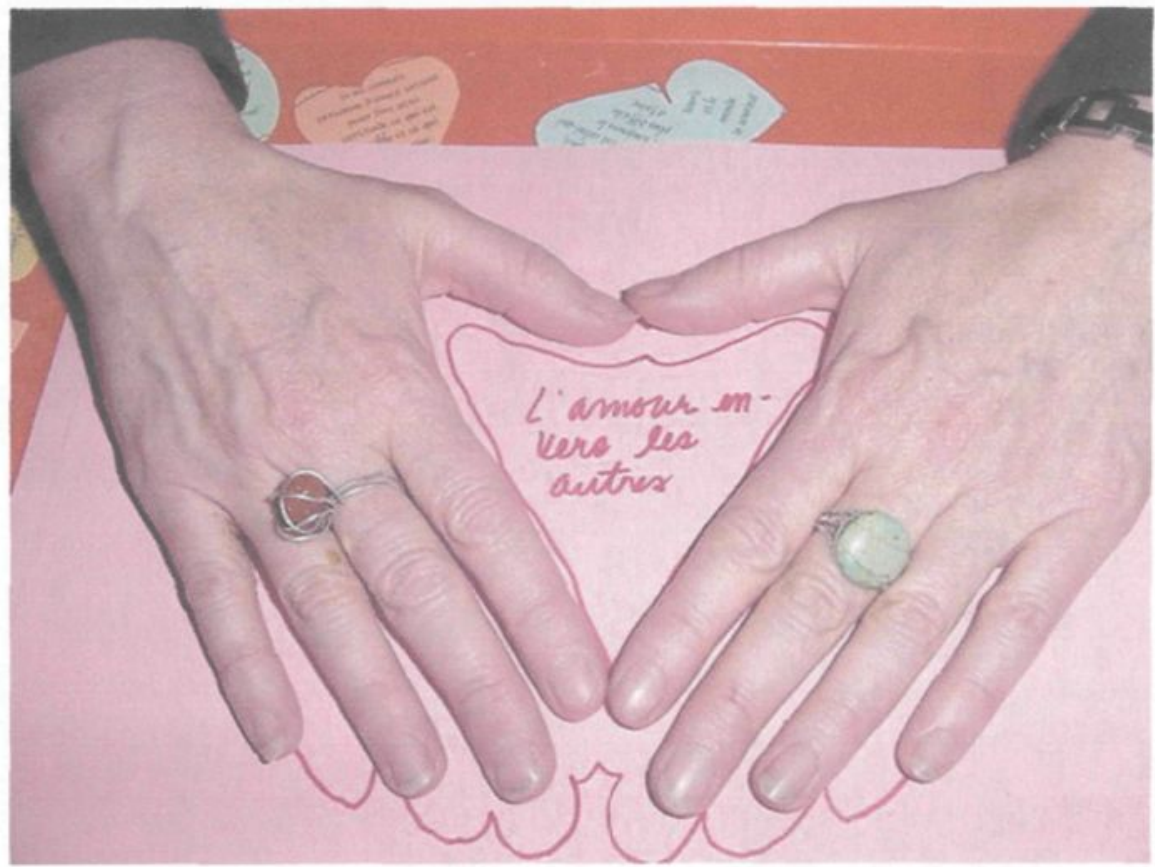

Mains poème l'amour envers les autres, Hutte de l'amour, fév. 2002

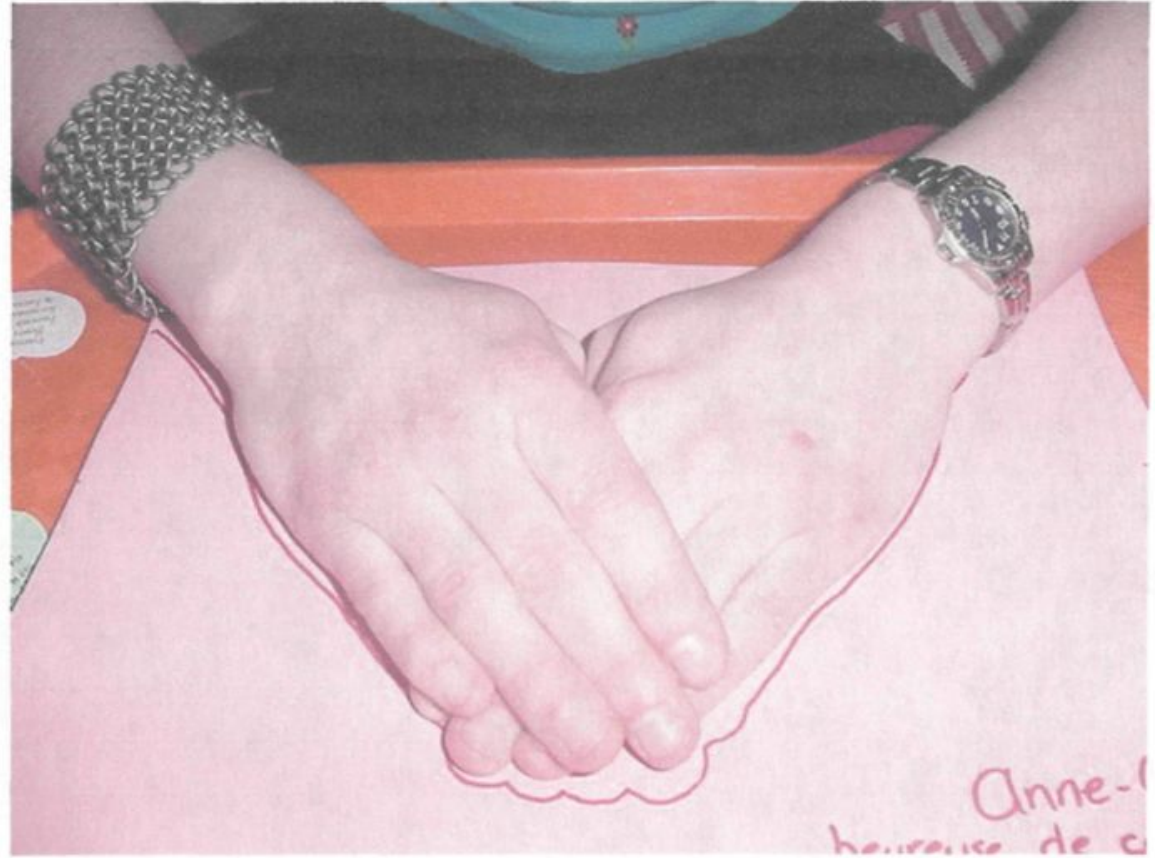

Mains poème oser et l'assumer, Hutte de l'amour, fév. 2002 


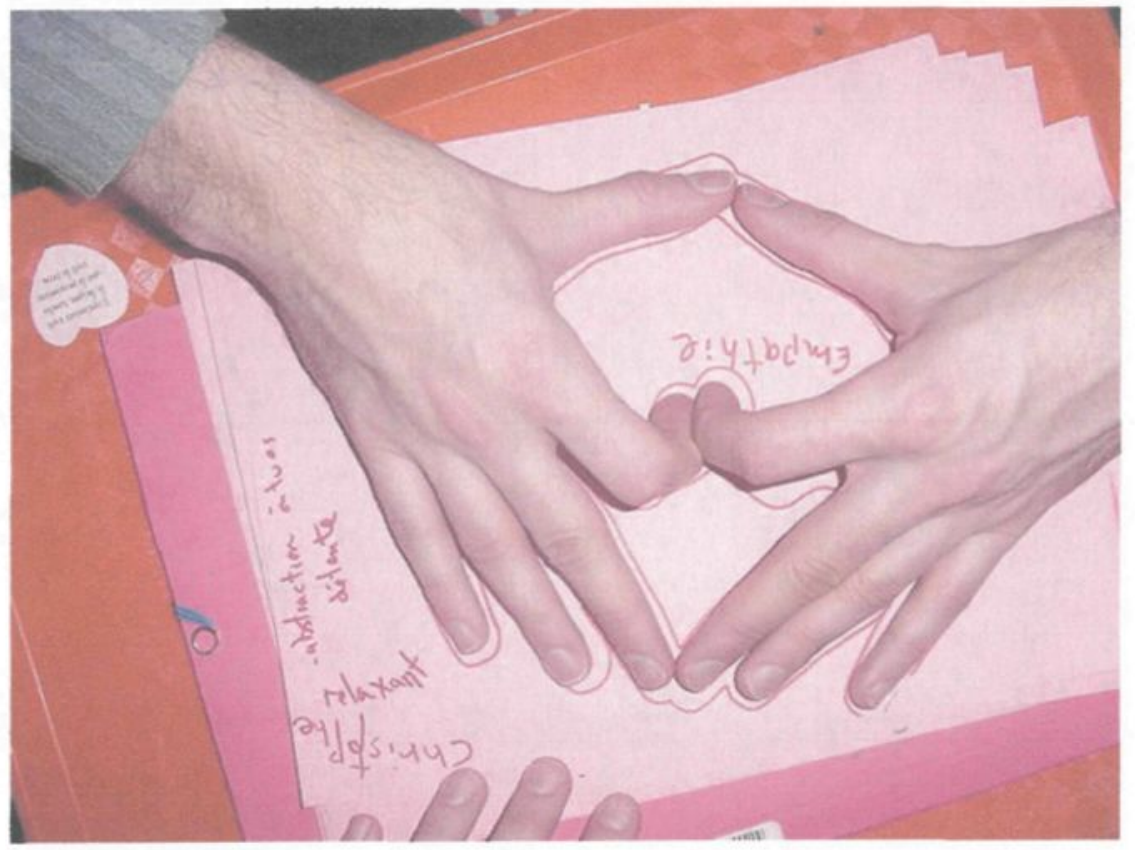

Mains poème empathie, Hutte de l'amour, fév. 2002

À mon sens, notre façon physique de réagir parle. L'atmosphère de convivialité et de plaisance des installations vise à établir un rapport de confiance qui ouvre les portes à la captation d'un état. Par la spontanéité, nous créons sur place un mélange de soi et de l'autre qui naît de l'échange, un pouls de l'être dans son moment.

Cette interaction vise à capter un moment d'ouverture, de complicité entre des gens qui, au préalable, ne se connaissent pas, mais par qui se côtoient tous les jours dans un environnement commun. Cette œuvre permet aux personnes « d'explorer des parties d'elles-mêmes auxquelles elles n'ont pas accès dans d'autres domaines de leur vie », Neumark (2003). Mon rôle en tant qu'artiste est de réunir au mieux possible les éléments, lieux, gens, atmosphères, afin que la magie opère, que la communication s'établisse, qu'il y ait rassemblement, recueillement, réalisation : « Il s'agit de développer nos fonctions. La 
culture n'a d'intérêt que si elle nous transforme, développant notre propre humanité pour nous rendre plus apte à assimiler l'univers et à agir sur lui. » Maffessoli (1992). Ce moment fragile, je le nomme « effleurement ${ }^{15}$ plutôt que rencontre, en raison de la très courte durée de l'interaction et de sa précarité ou fragilité. Accéder à l'espace de l'autre comporte une part de risque, une mise en vulnérabilité de l'artiste qui doit créer une situation, et s'y abandonner.

Dans mes débuts, j'accordais une importance, lors des actions, à ouvrir mon interaction aux étrangers et non aux amis ou à la famille. Je $m$ 'incitais alors à aller vers l'inconnu; courir la chance de découvrir de nouveaux territoires, de nouvelles personnes. Je me meftais au défi d'entrer en communication avec toutes sortes de personnes, d'initier des occasions qui autrement n'auraient pas eu lieu. Maintenant, avec le dernier projet, j'ouvre à toutes personnes, inconnues et connues, ce qui est une façon d'approfondir mes relations avec les gens que je connais déjà et, de peut-être ainsi découvrir de nouveaux côtés de leur personnalité.

Je travaille souvent de façon intuitive. $\mathrm{A}$ la base, pour $360^{\circ}, \mathrm{j}$ 'utilisai ma pratique en sculpture pour aller vers les autres. C'est̂ seulement après coup que je me suis « étonnée » devant les résultats photographiques. C'est à ce moment que je leur ai conféré une validité esthétique artistique. Pour ce qui est de Iso 140202, j'avais plutôt pensé ce projet en terme d'isolement des autres le soir de la St-Valentin, et c'est une collègue et amie artiste qui avait insisté pour filmer la distribution des cartes afin de documenter l'expérience. La perspective me gênait, car la caméra m'intimide et je ne voulais pas

\footnotetext{
${ }^{15}$ Terme proposé par Claudine Cotton, artiste du Saguenay, lors d'une présentation à l'école Toutout, 26 septembre 2003 . Il m'a semblé que ce mot rendait parfaitement ce que je voulais réaliser.
} 
pervertir l'expérience par le procédé de documentation. Par contre, après l'expérience, je fus satisfaite de voir le fil de l'action, car trop concentrée sur ce que j'avais à faire, je n'avais pas été attentive à tout ce qui s'était passé. En revoyant le film, je ressentais de la satisfaction par rapport à ce qui avait été accompli, et je validais sa valeur humaniste et artistique. Observer les gens émus, les regards remplis d'émotions qui jaillissaient de ce geste, de cette action, tout cela donne à voir l'émerveillement.

Pour Iso 140202 et Dr Strange Love, je portais un costume, ce qui m'amena à me questionner sur mon rôle, est-ce que par ce costume je me dois d'incarner un personnage, et si oui, quelles sont les caractéristiques de ce personnage? Outre le costume le soir d'Iso 140202, je restai moi-même sans personnage, le costume rouge et rose étant seulement une façon de souligner, de signaler l'occasion, soit la St-Valentin. Tandis que le soir de l'Halloween avec Dr Strange Love, j'empruntai véritablement le côté fou du personnage du film de Kubric, en parlant avec un accent, gesticulant et en simulant des spasmes. Contrairement au personnage du film, j'inversai son côté destructeur machiavélique en une aftention particulière vers la guérison de l'humain et la sauvegarde de l'espèce. Le fait de prendre un moment et de se pencher sur la souffrance humaine dans ce cas physique, et d'offrir un soin symbolique de réparation, ici exécuté par la pose d'un bouton sur la zone douloureuse, revient à ma volonté de vivre une expérience intime de soin dans un lieu public. La manipulation de l'aiguille près de la surface du corps du « patient » demandait une tranquillité d'esprit de la part de la personne qui restait immobile, concentrée sur l'action que j'étais en train d'opérer. De là l'idée de temps de méditation à ce que l'on est en train de faire, donner une importance spéciale à ce que l'on fait; un geste absurde qui donne à réfléchir, qui laisse une trace sur le vêtement. Un bouton de méditation. 
Le projet La Hutte de L'Amour offrait la possibilité de vivre une expérience intime dans ce lieu public impersonnel que nous habitons et que nous côtoyons tous les jours : le centre social de l'UQAC. Pour ce projet, la façon de documenter a été intégrée dès le départ au processus de l'expérience. Il s'agissait de prendre une photo des mains à un moment précis du rituel proposé par l'accompagnateur à l'intérieur de la maison, et que ce geste soit une partie intégrante du rituel.

\section{La continuité}

Dans la suite de la maîtrise, j'avais tout d'abord pensé à continuer dans la lignée de la St-Valentin en proposant une activité d'accompagnement « main dans la main » pour les gens qui traversent la passerelle aérienne reliant le pavillon Principal au pavillon des Humanités. J'ai donc élaboré un système qui idéalement documenterait l'événement sans le pervertir, mais ce lieu très confiné me dissuada. Pour moi qui veux ouvrir l'expérience de vivre quelque chose d'inattendue orientée sur l'exploration, il me fallait faire plus de place à l'imprévu, à l'autre, au lieu; ce projet devenait trop dirigé. Je gardai donc l'idée d'une marche à deux dans l'université où je choisis le point de départ, le point $\mathrm{A}$, en laissant l'autre choisir le point $\mathrm{B}$, le point d'arrivée. Suite à quoi, on prend un moment pour inscrire ce geste à travers une ouvre picturale que l'on crée ensemble. Ce temps planifié et choisi par les deux crée le moment.

Le premier point $\mathrm{A}$, le point de départ que je choisis est situé dans la passerelle aérienne de l'UQAC qui relie le pavillon principal à celui des Humanités. Le premier point B sera déterminé par le participant. Ce qui m'amènera à vivre des moments aussi diversifiés que l'éventail des gens qui se prêtera à l'expérience. Mon défi est de trouver un «...dosage adéquat entre l'expression pleine et entière de soi et une saine capacité d'entrer 
en rapport avec autrui...un exercice complexe d'équilibre dynamique qui dure toute une vie » Neumark (2003). Cuvre où «... chaque individualité gère sa propre forme à travers son comportement, sa manière de se présenter et de s'adresser aux autres» Bourriaud (2001). L'expérience sera offerte sur différentes plages horaires, en accord avec les participants. Plutôt que d'en faire un événement spectaculaire, je veux préférablement insérer cette action dans le quotidien, et en prolonger la durée. Je veux laisser le bouche à oreille faire son travail.

Dans le cadre de Iso 140202, j'ai fait appel à des jeunes pour écrire dans les cartes en voulant sensibiliser les ados à la réalité du suicide. Tandis que pour La Hutte de l'Amour, les collaborateurs étaient impliqués directement dans l'expérience, prolongeant ainsi la durée de l'oeuvre, car je ne pouvais assumer seule une présence constante. De plus, la collaboration donne la possibilité à l'expérience de prendre différentes formes. L'idée de faire de cet événement un regroupement, confère à celui-ci une force qui va au delà de mon propre courage. L'effet d'entraînement d'un groupe donne une énergie particulière à l'expérience et demande du détachement, une distance face au contrôle de la situation. Dans mon dernier projet, je ne ferai pas appel à des collaborateurs, car je veux vivre l'expérience seule, idéalement avec détachement, laissant place à l'autre pour ainsi découvrir en même temps que l'autre, un moi, un nous en rapport avec le lieu.

Pour les marches, contrairement aux interventions précédentes, j'élimine les accessoires lors de la rencontre, ce qui est un défi pour moi, car sans les décors et les costumes soutirés, je me retrouve moi-même sans artifice face aux autres. Cela implique une véritable mise en vulnérabilité, car il n'y a aucun élément derrière lequel on peut se cacher. La collaboration avec des gens de différents domaines, entre autres les sciences 
sociales, ne sera pas nécessaire dans ce cas à moins qu'ils veuillent participer comme «marcheurs ». Je ne veux pas faire appel à une équipe, je m'en remets à la curiosité et à la générosité de la population universitaire. Je tiens à laisser les gens venir vers moi, plutôt que de faire la majeure partie du chemin. Je peux m'attendre à une moins grande popularité que dans le passé, mais je compte sur le fait que la qualité de l'expérience d'échange en sera grandie. Suite à la marche, imprégnés du moment vécu, ensemble, nous peignerons une cuvre bidimensionnelle inspirée de l'expérience vécue. Par contre dans la phase finale de l'œuvre qui est une bande son, l'expérimentateur utilise un lecteur de disque compact et un casque d'écoute qui sont des accessoires très présents et importants pour la diffusion de l'œuvre. 


\section{Chapitre 5}

\section{Présentation de l'œuvre}

et description d'expériences de projet de fin de maîtrise

\section{Laisser entendre, murmures suggestifs}

« La poésie n'est pas une inspiration, mais bien une expiration »

Gainsbourg $^{16}$

L'œuvre se présente sous forme de processus en perpétuelle transformation. Chaque expérience rencontre une étape pour la constitution d'une méthode d'intervention artistique à vocation sociale. L'ensemble des gestes et des œuvres peintes a donné naissance à une oeuvre portrait à caractère sonore qui est l'étape concluante du processus : l'étape finale. Cette recherche n'a pas de fin et génère et se regénère sous différentes formes. Je dirais à l'infini. Alors dans le cadre de la maîtrise, j'ai choisi de conclure l'expérience par l'appropriation d'un certain nombre de rencontres en créant une trame sonore qui suggère un parcours, une invitation à vivre un autre moment. Ce parcours est suggéré par un enregistrement audio ${ }^{17}$, inspiré de mes différentes expériences d'effleurements et de marches symboliques. Le trajet est libre sur le site de l'université et s'exécute seul avec le système audio. Les participants volontaires choisissent leur itinéraire. L'enregistrement a

\footnotetext{
${ }^{16}$ Citation entendue à la radio de radio-Canada émission Indicatif Présent, érnission du 19 mars 2004

${ }^{17}$ Pour une description du contenu, voir Annexe A, ou écouter la bande son joint à cet essai
} 
une durée de 17 minutes, et les « auditeurs expérimentateurs » sont libres de prolonger l'expérience. Cette ambiance sonore interprète et suggère l'atmosphère du moment vécu lors de la démarche que j'al expérimentée avec chaque personne. S'ajoute l'exposition des cuvres peintes qui ont été réalisées lors des marches des expériences précédentes. Ces œuvres sont exposées à différents endroits dans l'université pour une période d'un mois. 


\section{Conclusion}

Tout ou long de ma recherche, je me suis confrontée à différents questionnements, dont celui de déterminer ce que serait l'œuvre finale, mon travail étant davantage centré surr le processus.

Vu le caractère social et expérientiel de l'œuvre, la présente recherche comporte certaines difficultés à fixer l'œuvre qui se veut en perpétuelle évolution. Une œuvre qui est une expérience humaine, et qui une fois vécue, trouve refuge à l'intérieur de la pensée et du comportement même du participant. Voulant donner forme à des interactions humaines, l'œuvre se retrouve en perpétuel mouvement, à l'intérieur d'un groupe social comme à l'intérieur de chaque participant ou témoin. Il m'est plutôt difficile de définir la forme globale de l'étendue de l'œuvre et ses répercussions. C'est pour cela qu'au terme de l'expérience, je garde les traces comme une mémoire de ce qui s'est passé dans l'échange, pour ensuite inscrire dans le lieu une œuvre in situ qui fait référence à cette rencontre et qui fait appel aux sensations dégagées lors de l'expérience en lien avec les gens et le lieu. Cette intervention vient en quelque sorte boucler un cycle en marquant un territoire comme espace « humain » humanisé.

Par contre, ces œuvres, ces interventions, me conduisent à me poser plusieurs questions à caractère éthique : si les expériences que je propose s'insèrent dans un processus de création artistique pour lequel l'artiste et l'autre deviennent une forme de 
matériau, à qui appartient l'cuvre et où s'arrête mon droit de manipuler ce matériau? De là le désir d'une appropriation de l'expérience dans ma dernière mancuvre. D'organiser ces marches rituelles me permet avant tout de découvrir moi-même différents lieux dans mon propre environnement pour ensuite le faire découvrir aux autres. Je m'intéresse plus spécifiquement aux rapports humains; ce qui m'amène à faire de l'art engageant ou motivant un rapport social. Ces actes deviennent une source d'inspiration puisée à même ce qui m'entoure, me fascine. Mon intérêt pour l'être humain et pour ses comportements m'amène vers l'autre, qui, pour moi, devient à la fois source d'inspiration et miroir de moimême. Il y a différentes façons de se voir, d'être, et ce, en fonction du milieu réfléchissant. D'une certaine façon toute œuvre actuelle comporte un potentiel social ou a un impact sur le social, donc l'artiste est, doit être responsable de son œuvre. Suite à ces réflexions, je suis en mesure d'affirmer que l'œuvre m'appartient.

\section{Se donner rendez-vous}

« Avoir une pratique artistique, c'est être capable de déployer avec esprit et finesse son intériorité en la rendant partageable. »

\section{Massimo Guerrera, $2000^{18}$}

Suite à toutes ces expérimentations, je considère que l'UQAC a été un milieu fertile et prévilégié d'apprentissages et d'échanges. J'ai su y élargir mes champs de compétences et de connaissances tout en consolidant une confiance en ce que je fais, car je me lance souvent dans une action sous l'impulsion d'une idée qui prend son sens dans l'acte de faire

${ }^{18}$ Artiste montréalais, cité dans Les commensaux quand l'art se fait circonstance , Montréal, Skol, $243 \mathrm{p}$. 
à travers l'échange. Certes, il y a eu des moments de doute, liés à la fatigue ou à la confrontation des esprits rationnels. Je ne peux dire que j'ai résolu l'intense questionnement lié à la quête de sens dans l'absurdité. Je crois avoir contribué à donner une visibilité, une façon de voir ou de faire de l'art à l'université en créant des plates-formes de communication. Je suis venue étudier à Chicoutimi pour la proximité de la nature et l'ambiance personnelle qu'offre une université en région. Il m'a donc été plus facile de vérifier et de sentir l'impact des actions artistiques que j'ai initiées dans la communauté, car le retour dans l'échange et le dialogue était essentiel à mon travail de mâtrise.

Le cheminement des actions que j'ai pu expérimenter au cours de cette maîtrise est parti d'un acte individuel dirigé vers une personne cible avec une intension précise, pour ensuite se transformer en un travail d'équipe organisé sur plusieurs jours où les collaborateurs deviennent participants et laissent ensuite place à la libre participation des passants. La hutte de l'amour impliquait plusieurs personnes dans l'organisation, et conférait un côté festif et spectaculaire au projet. J'ai préféré, par la suite, un retour à l'acte individuel plus discret basé cette fois-ci sur le consentement de la personne : les marches accompagnées. Le dernier parcours, marché seul, est symboliquement l'apprivoisement de ma propre solitude.

L'étape finale de l'œuvre englobe une nouvelle expérience, les traces ainsi qu'une trame sonore; toutes formes d'expressions que j'ai développées lors de mes études. Je n'ai pas trouvé de réponses satisfaisantes à la question éthique, à savoir : quel est mon droit d'exposer les traces d'une expérience dans laquelle les participants se livrent? Pour l'instant, j'expose ces traces avec l'accord de la personne ou en préservant l'anonymat des 
gens. Je fais appel à ma sensibilité et à mon propre jugement. Certaines questions restent en suspens.

L'artiste est un observateur penseur, une forme d'athlète du muscle de la pensée. L'athlète s'entraîne, perfectionne sa technique et fair de la visualisation pour être à son maximum le jour de la compétition. En tant qu'artiste, le muscle à entraîner est, à mon avis, la société. Chaque individu qui constitue le groupe social représente une fibre, une cellule de ce muscle. Les mentalités, les valeurs et les idéologies rassemblent les gens; l'artiste comme l'athlète se soucie de la forme. Dans ce cas, la forme à devenir est celle du bonheur. Le bien-être de chaque individu qui constitue une société est directement relié à ce qui l'entoure. Nous baignons parmi les valeurs véhiculées par ceux que nous côtoyons.

Pour ce qui est de mes projets futurs, je souhaite continuer ma recherche et idéalement m'affilier à un réseau de centres ou de galeries déjà instaurés, ce qui me permettrait de satisfaire mon désir de mettre en contact une forme d'art avec un public qui ne fréquente habituellement pas ces lieux. II semble y avoir une tendance chez les artistes de la relève qui souhaitent un rapprochement de l'art et de la vie dans des endroits publics. Je m'intéresse au corps social et à l'idée de communauté. Je pense avoir développé des habiletés quant à l'approche des gens, en suscitant un intérêt, une curiosité qui serait un atout pour la transmission, voire l'enseignement. Je compte continuer à travailler à créer des liens entre différentes choses ou disciplines qui, par leur mise en relation, nous ouvrent sur de nouvelles possibilités. Depuis quelques mois je fais partie d'un groupe de musique, j'apprends énormément de ce travail de création en équipe et continue à explorer les possibilités du son, de l'échange et du jeu. 
Toujours dans un but de permettre la mise en contact, l'évolution par la perméabilité des gens qui fréquentent un lieu, je veux donner place à l'ouverture à travers l'échange avec les autres. Les outils que nous utilisons pour explorer le monde déterminent en grande partie les découvertes que nous allons y faire. Dans toutes formes d'expressions, quelle est la part du «moi », du « tu » et du « nous »? Quelle est la nature du temps et du lieu dans lequel il se déroule? L'examen de ces conditions est enchevêtré au besoin de parler et d'être en compagnie d'autrui. Un être humain seul sur une ̂le déserte est-il toujours « humain »? L'Art, une forme qui rend possible l'expression par une forme qui reconnaît cette possibilité.

«Supposons que vous regardiez un ciel dégagé et que vous attendiez qu'un nuage se forme -vous pourriez apprendre quelque chose sur la nature. Supposons que vous attendiez plus longtemps, que le ciel s'éclaircisse à nouveau-vous pourriez apprendre quelque chose d'autre sur vous-même. »

-Allan Kaprow, 1996 


\section{Illutration A}

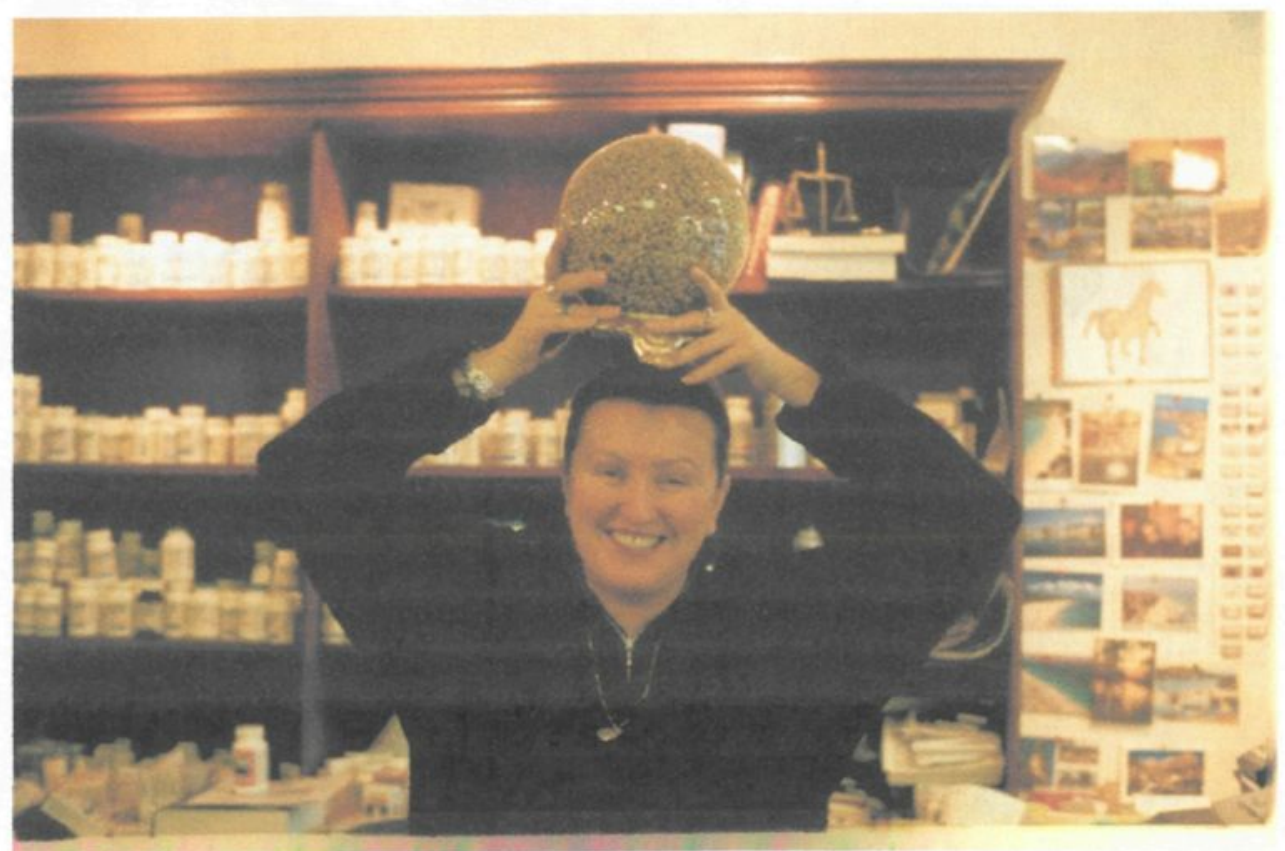

Milenka, $360^{\circ}$, Toronto 2001

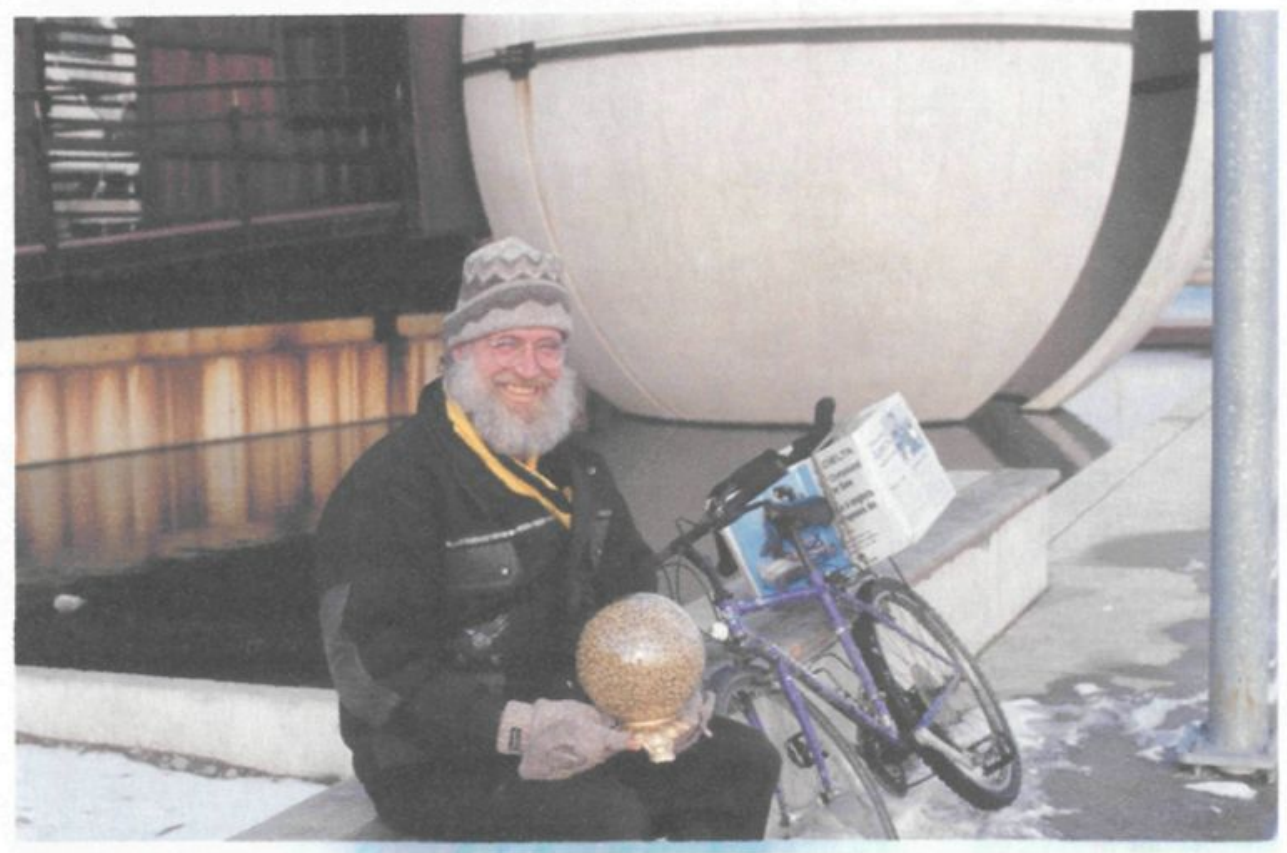

Le philosophe, $360^{\circ}$, Toronto 2001 


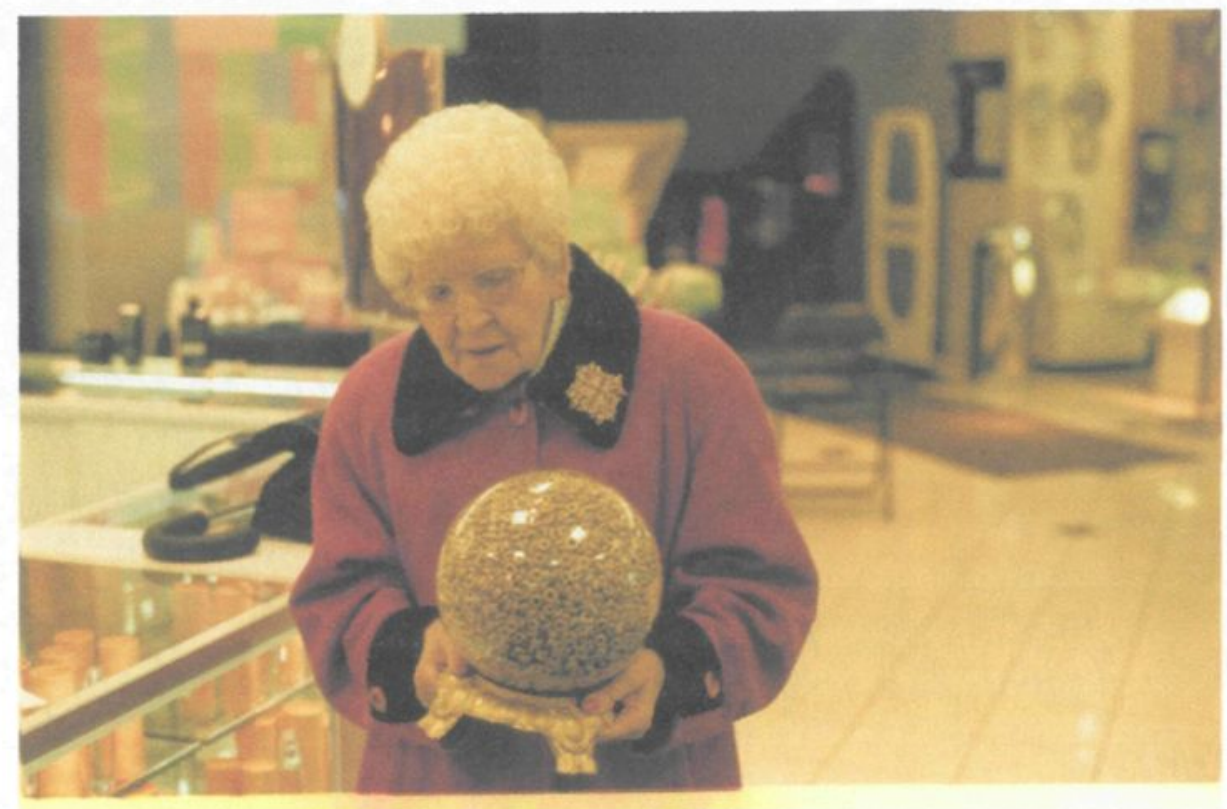

Angela, $360^{\circ}$,Toronto 2001

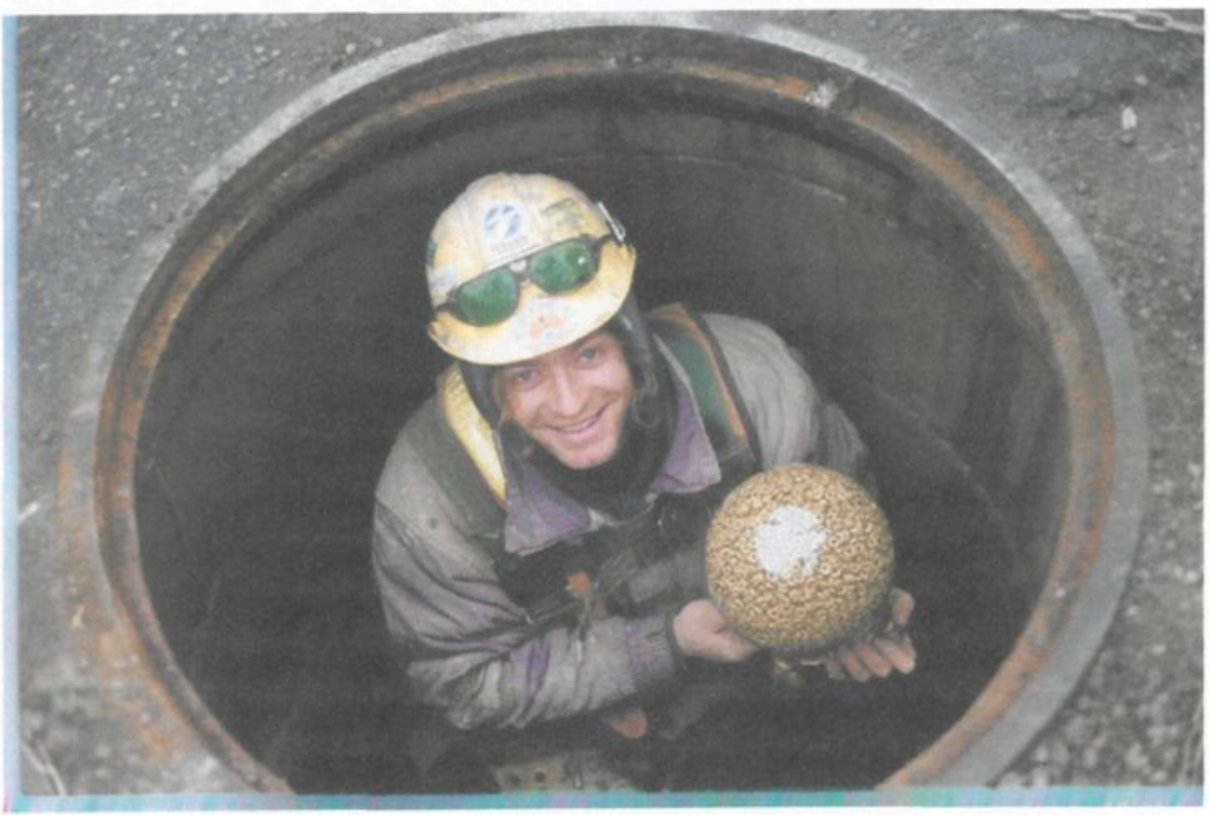

Jonny, $360^{\circ}$, Toronto 2001 


\section{Illustration B}

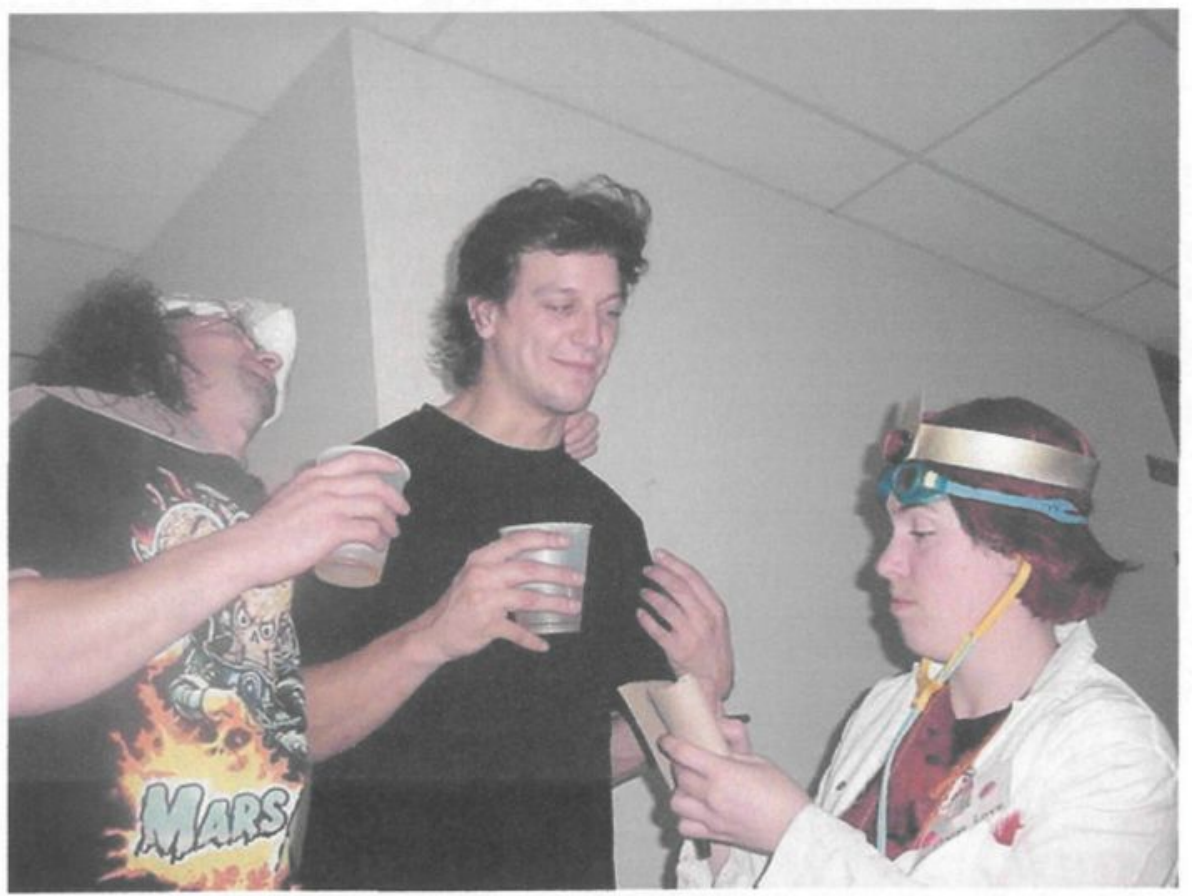

Consultation, Doctor Strange Love, octobre 2002

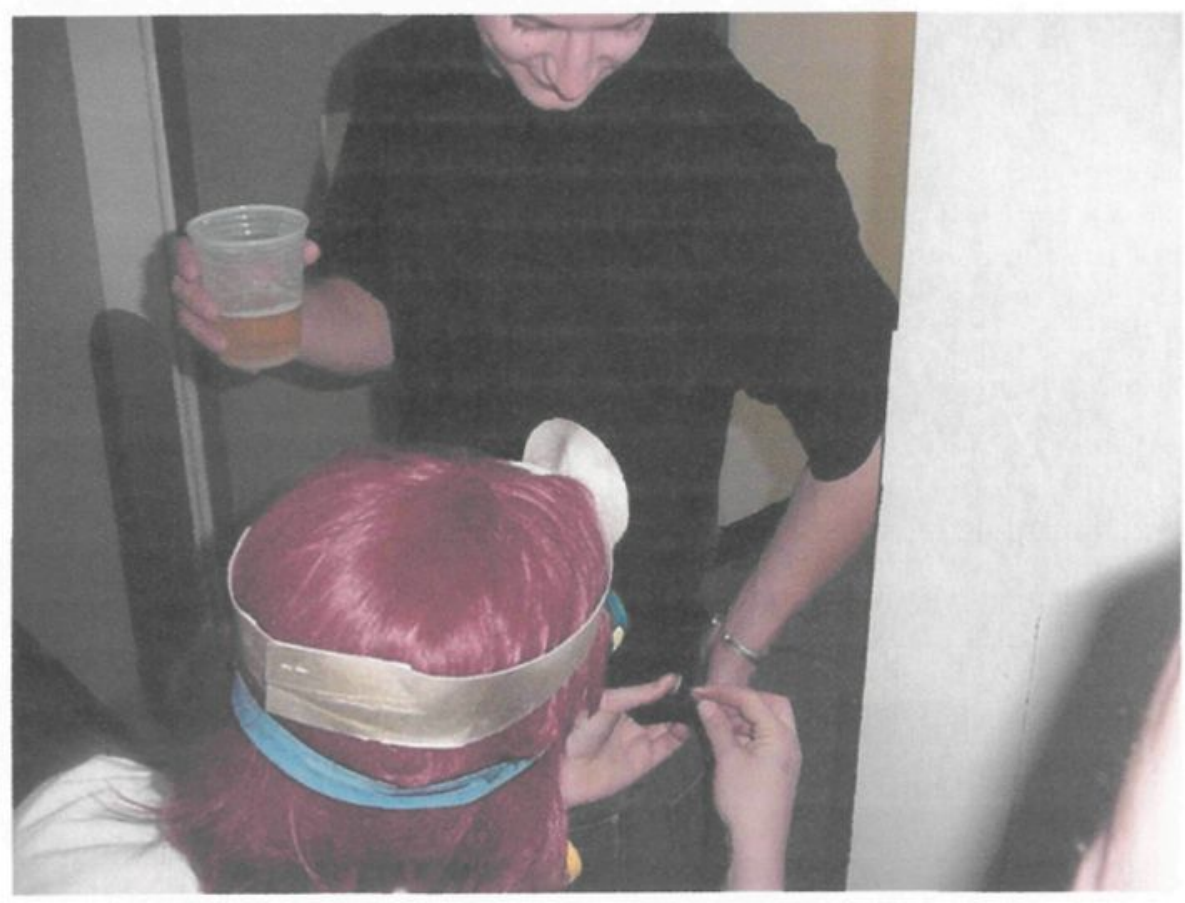

Couture du bouton, Doctor Strange Love, octobre 2002 


\section{Illustration C}

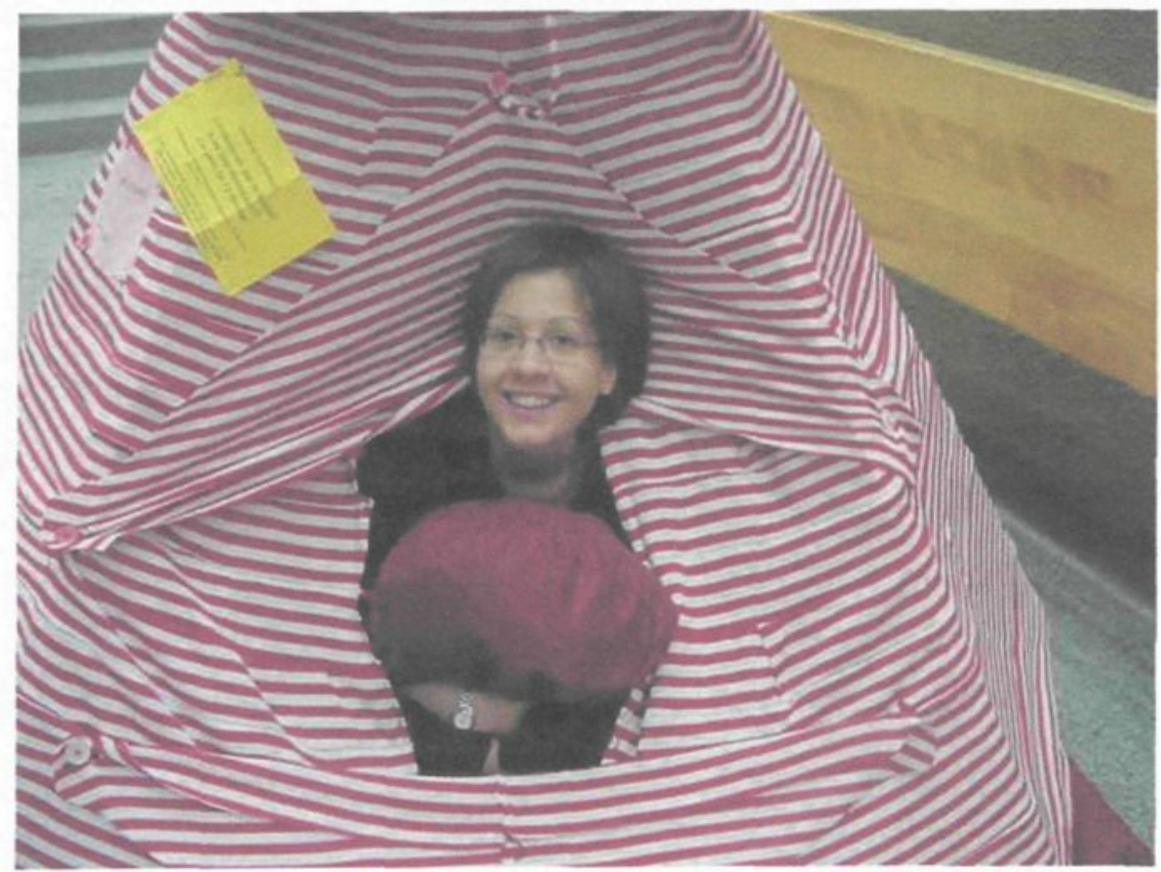

Rita, collaboratrice, Hutte de l'amour, fév 2002

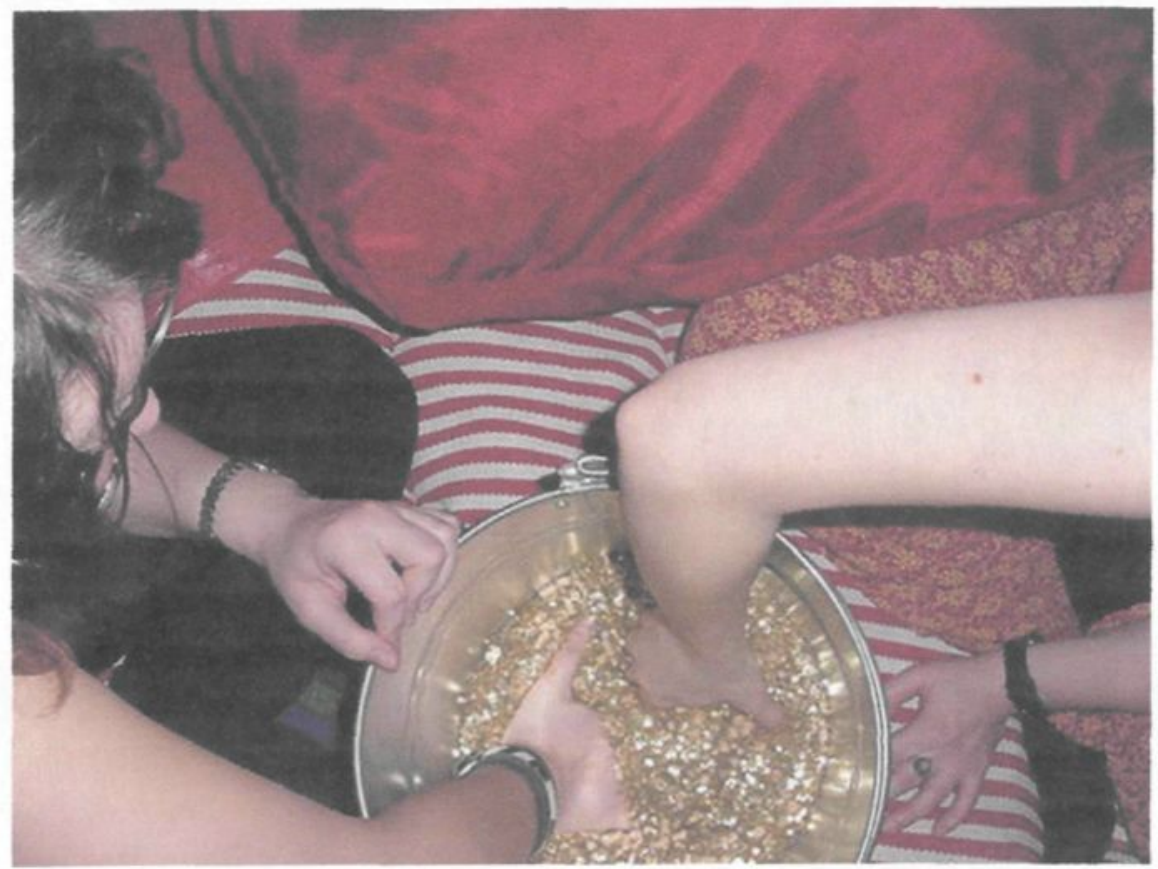

Étape 2 du rituel, Hutte de l'amour, fév 2002 


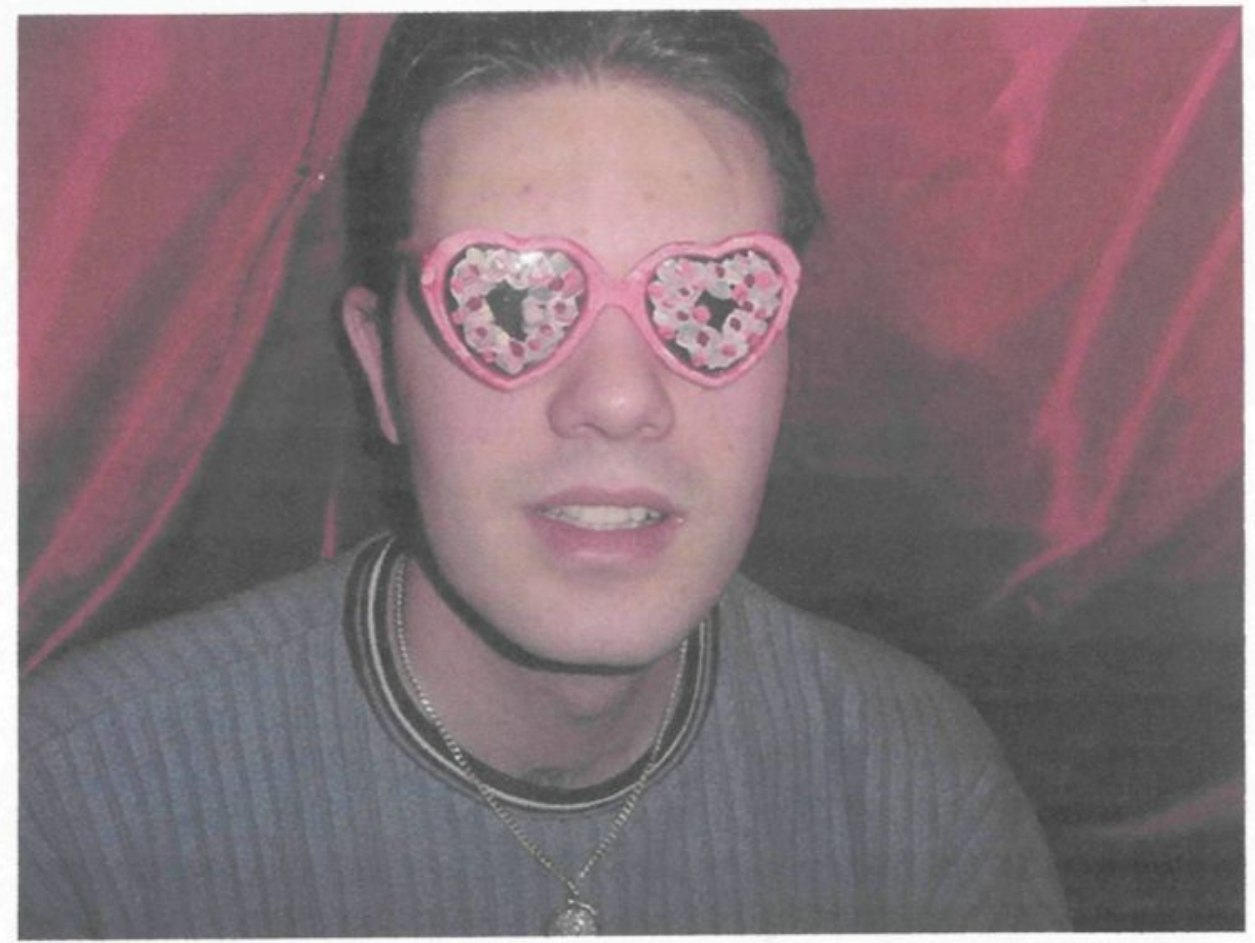

Christophe, collaborateur, Hutte de l'amour, fév 2002

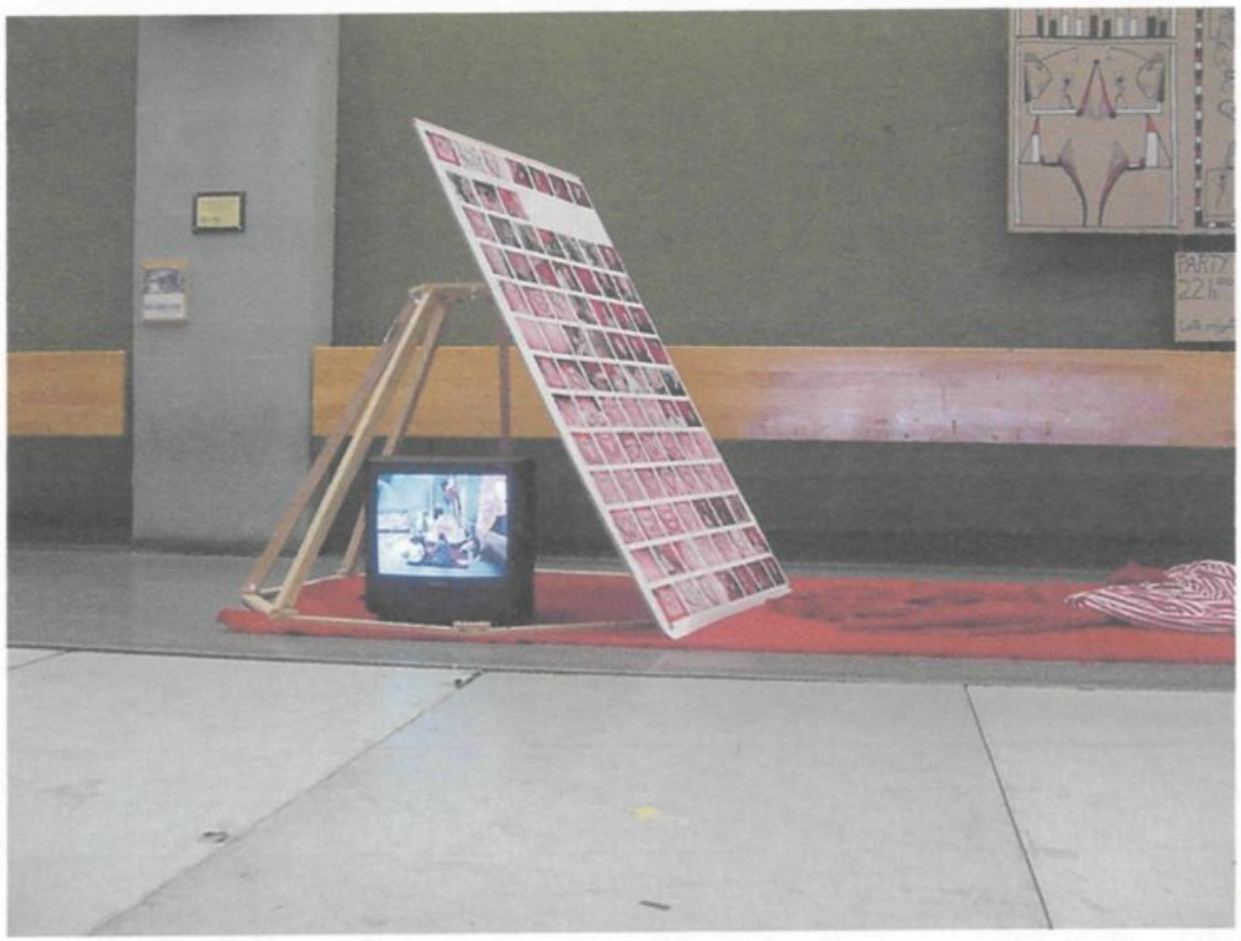

Installation phase finale, Hutte de l'amour, fév 2002 


\section{Annexe A}

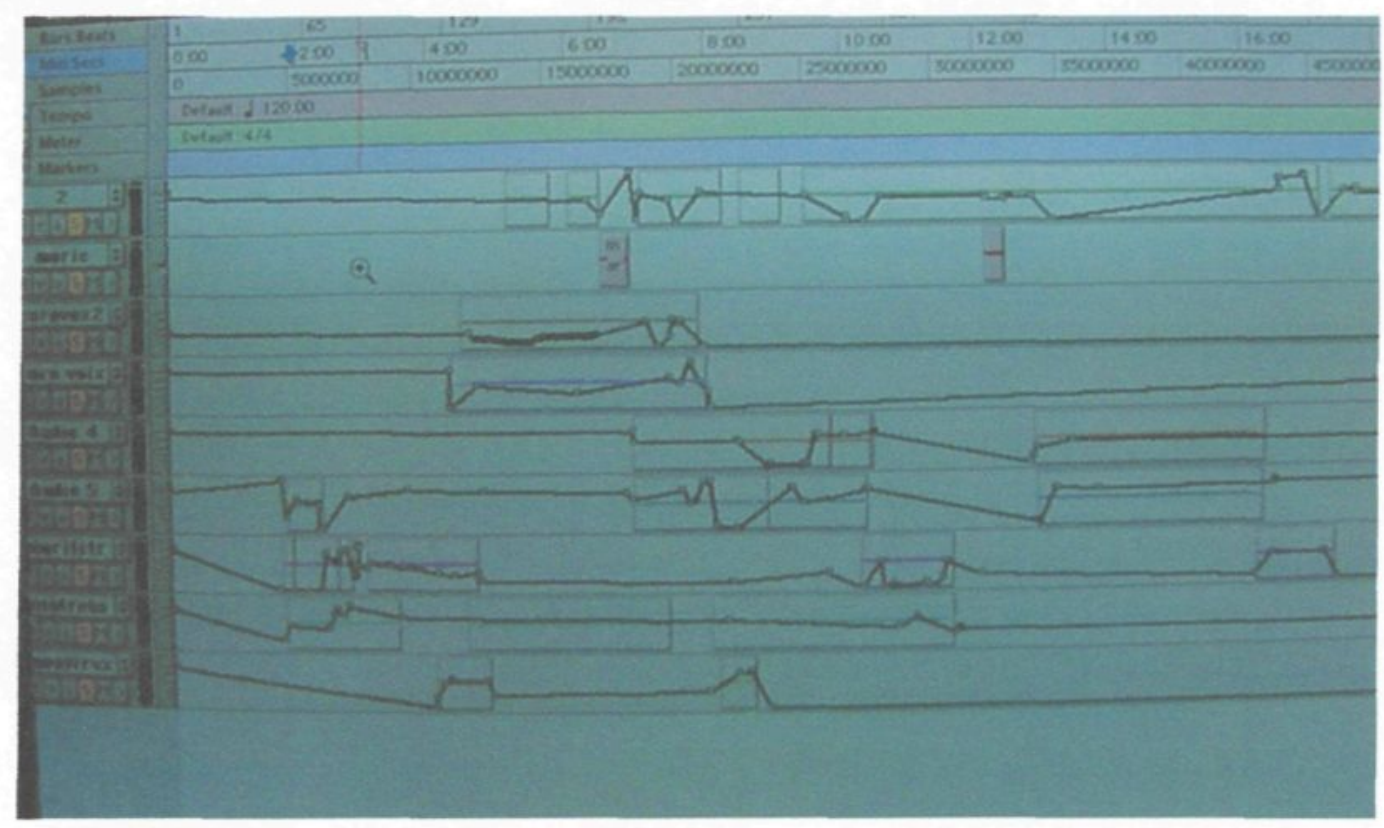

Montage sonore, Bande son, phase finale œuvre septembre 2004

Participation voix dans l'odre d'apparition

Nadia Bertrand, animateur radio, Marie-Ève Émond

Chant Caroline Tremblay

Instruments et son Digeridoo, contrebasse, enregistrement cd qui saute, 


\title{
Les inspirations
}

\author{
Descriptions des effleurements
}

\section{Julie}

J'ai tout d'abord partagé cette expérience avec une amie, Julie Alain, qui travaille au service de relation d'aide de l'université. À ce temps, je n'avais pas encore élaboré l'idée de la marche, alors nous sommes directement passées à l'atelier. Nous avons choisi de peindre sur une toile de grande dimension, soit de $150 \times 126 \mathrm{~cm}$, que j'avais préparée au préalable. Placées côte à côte nous commençons ce grand canevas, alternant pinceau et spatule. Après un certain temps, environ dix minutes, nous changeons de côté afin de participer à l'entière surface du tableau, reliant ainsi nos interventions. Du beige, du rose, du rouge, du bleu, cette gamme de couleur constitua le fond qui a été créé dans la joie. Je me suis mise à étendre la peinture avec un morceau de carte de crédit coupée, ce qui a bien fait rire ma coéquipière, qui a voulu essayer à son tour. Je considère cette expérience comme étant le trajet d'une libération de créativité, ainsi que l'apprivoisement de la confiance. Une fois le tableau recouvert de peinture, nous nous sommes reculées pour mieux le voir dans son ensemble. Le temps de discuter et de prendre une collation. J'ai trouvé dans une boîte des personnages que j'avais découpés d'une affiche qui annonçait une pièce de théâtre que je proposai de coller sur notre tableau. Un peu septique Julie considèra cette option. Elle me demande alors si j'avais prévu le coup, je lui répondis que non, que j'avais découpé ces figures de femmes sans vraiment savoir ce que j'allais en faire, et que je trouvais qu'elles avaient leurs places sur notre peinture. Elle pris un moment pour bien regarder et appuya mon initiative. Nous collâmes donc ces femmes aux bras ouverts sur le tableau. Suite à quoi il suffit de quelques ajouts et le tableau était complété. L'inspiration du titre vient de Julie : À Toutes Celles qui ont retrouvées leur dignité un hommage aux femmes de la Polytechnique qui sont décédées le 6 décembre 1989, le tableau ayant été peint le 5 décembre 2003 en fin de soirée.

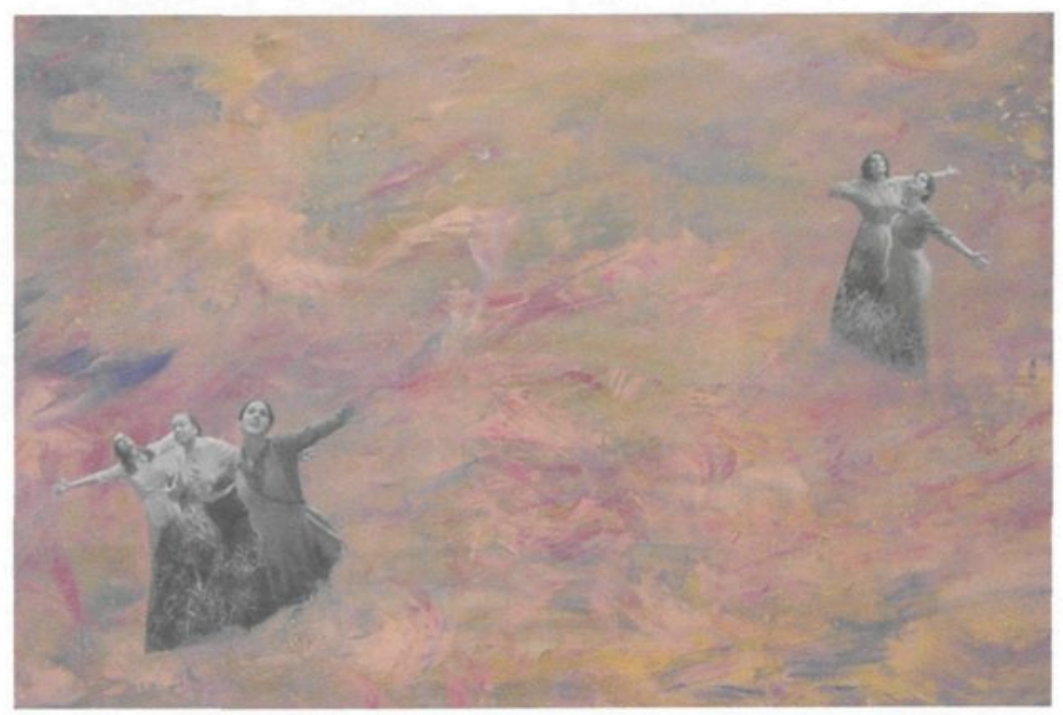

À Toutes Celles qui ont retrouvées leur dignité, 2003, acrylique, papier, feuilles d'or 


\section{Françoyse}

Françoyse Lamontagne, l'infirmière de l'université, se propose à l'expérience. Femme très occupée, nos horaires ont pris un certain temps avant de trouver le moment opportun de la rencontre. Nous avons opté pour un grand format, le canevas est plus carré que rectangulaire. Le cadre mesure $175 \times 112 \mathrm{~cm}$. Nous avons soupé à l'atelier, partageant des aliments que nous avions amenés. Ce qui m'a vraiment surpris lors de ce souper, c'est la qualité et l'intensité de deux silences qui se sont succédés lors du repas. Françoyse et moi étant des femmes volubiles, nos rencontres très animées nous offrent rarement l'occasion de vivre un silence. Ce soir fut très particulier pour cette raison, à un moment, nous avons cessé de parler, nos regards étaient l'un dans l'autre et ils ont pris des allures paisibles. Aucune des deux ne semblait vouloir briser ce moment harmonieux de paix. Nous sympathisions sans avoir à se parler. Je garde un souvenir très positif de ce moment, qui se reproduira plus tard dans la soirée. Suite au repas, nous nous en sommes remis aux pinceaux, du vert lime choisi par Françoyse et du beige de mon côté constitua la majeure partie des grands traits spontanés appliqués sur la toile. Après 10 minutes, le tableau était terminé, c'est ce que l'on a compris par la suite, car dans notre élan, nous n'avons pas su nous arrêter à ce moment. C'est comme si ça n'avait pas de bon sens de terminer cette expérience si tôt. Alors nous avons continué à ajouter de la peinture. Lorsque l'on prit un repos et du recul pour mieux regarder le tableau, on se rendit compte que nous sommes allées trop loin et que quelques minutes auparavant, nous avions déjà accompli quelque chose de complet, tandis qu'en ce moment nous étions face à un trop plein. Après une longue pause, nous avons commencé à coller toutes sortes de substances sur la toile genre sel, café, riz, ce qui ajoutait en texture. Nous avons tourné le tableau dans différentes directions pour voir s'il n'y avait pas un sens plus intéressant qu'un autre. Après s'être mises d'accord sur un sens, nous avons ajouté la touche finale, il était déjà 22 heures. $^{19}$

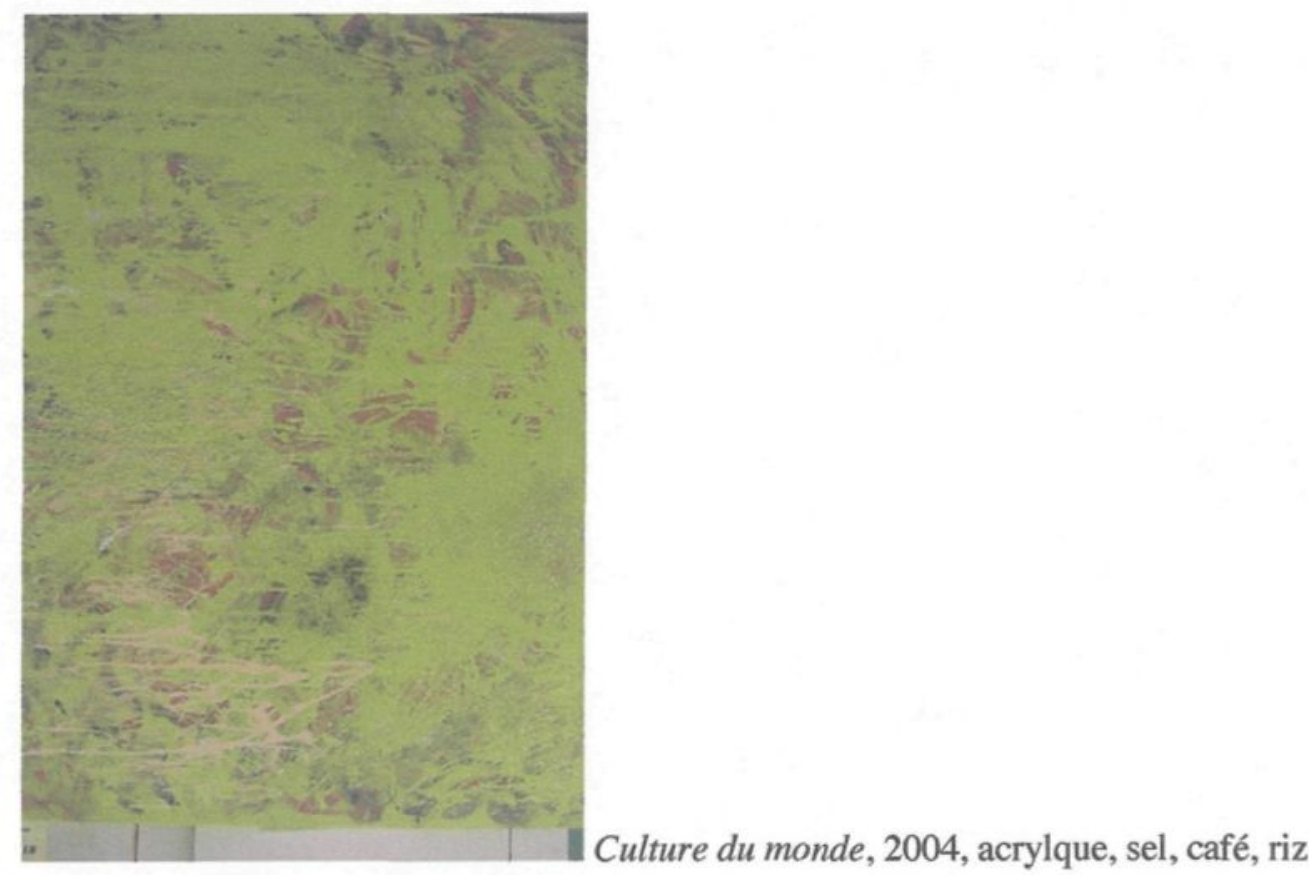

${ }^{19}$ Le temps que le tableau sèche pendant la nuit, car ce tableau ainsi que celui exécuté avec Julie ont été exposés à l'intérieur des cages d'escalier du pavillon principal, dans le cadre du projet Escaliers Vivants en avril 2004, un projet initié par le département d'éducation. 


\section{Valérie}

Valérie, collaboratrice dans le projet de la hutte, était très enthousiaste à l'idée de participer à cette nouvelle expérience. Je ne la connaissais pas beaucoup, par contre je me sentais assez en confiance pour me lancer dans un premier essai avec elle. On se donna rendez-vous un lundi matin du mois de mars. La première étape était la fabrication de la toile qui allait devenir la surface à peindre suite à notre marche. L'idée était de construire une toile selon des dimensions bien précises. La longueur du bras de Valérie définissait la hauteur de la toile, tandis que la longueur aurait la mesure de mon bras. La construction du canevas prit une partie de l'avant-midi, et vu le manque d'expérience de Valérie dans le domaine, je me retrouvais à faire le canevas presque seule, en me sentant très mal à l'aise de ne pas savoir comment inclure Valérie dans ce processus. Une fois la toile tendue sur le canevas, Valérie reçut un appel sur son téléavertisseur. On décida donc de continuer l'expérience le lendemain matin. Elle proposa de déjeuner à la cafétéria de l'université, et j'accepta. J'étais très contente de voir Valérie prendre des initiatives en proposant des actions. Le soleil se lève et je me sens disposée à vivre cette expérience que je sentais importante et privilégiée. Durant le déjeuner, un étudiant vint se greffer à nous.

La prochaine étape nous amenait vers la marche, comme prévu nous nous dirigeons vers la passerelle. Ce fût spécial de rencontrer et de converser avec des gens que l'on croisait tout en sachant que l'on conférait à ce qui se passait dans le moment une attention spéciale, qu'eux ne soupçonnaient pas. Une fois rendu à mi-chemin de la passerelle, on a pris un petit moment d'arrêt, le temps était très ensoleillé, et à ce moment la passerelle est un lieu de prédilection. Quelques personnes interrompirent leur parcours pour discuter quelques instants avec nous. Une fois prêtes, on initia la marche. Je me laissai guider par le moment et d'une certaine façon par Valérie qui savait où, géographiquement nous allions. Nous marchions d'un pas lent, à chaque pas le temps semblait ralentir de plus en plus jusqu'à être suspendu. Nous avions créé une bulle intemporelle, ce rythme me permit de sentir ce lieu, une partie du couloir du $2^{c}$ étage du pavillon principal, avec une approche différente. Ce qui me conduisit à une perception différente des lieux, une perméabilité qui me rendait hypersensible aux moindres petits détails. Par exemple, j'ai remarqué les variantes de tonalité de tons dans la brique, j'ai ressenti une paix intérieure, un moment d'union avec mon environnement. Lorsque nous sommes arrivées sur le bord des fenêtres, près des plantes dans le centre social, je compris que notre marche prenait fin là, regardant les derniers amoncellements de neige dans la cour extérieure, je sentais que nous venions de vivre un moment beau et unique.

Suite à quoi nous avons été à l'atelier pour fixer cet instant sur toile. Valérie manifesta très clairement son désir de peindre avec les doigts... pas de problème. Nous avons choisi de peindre un monochrome (l'utilisation d'une seule couleur) en l'occurrence le bleu. Le tableau s'élabora dans la spontanéité et dans une très belle collaboration. Ça n'a pas pris beaucoup de temps pour sentir qu'il était complété. Étant donné que c'était ma première expérience, je ne savais pas trop comment conclure. Nous venions de vivre un moment intense de partage et il fallait un certain courage pour quitter cette énergie. Ni Valérie ni moi ne semblions vouloir mettre fin à ce moment précieux par la séparation. Néanmoins, il était presque midi et dans mon emploi du temps, qui en général est assez chargé, j'avais un rendez-vous, ce qui facilita l'aurevoir. 


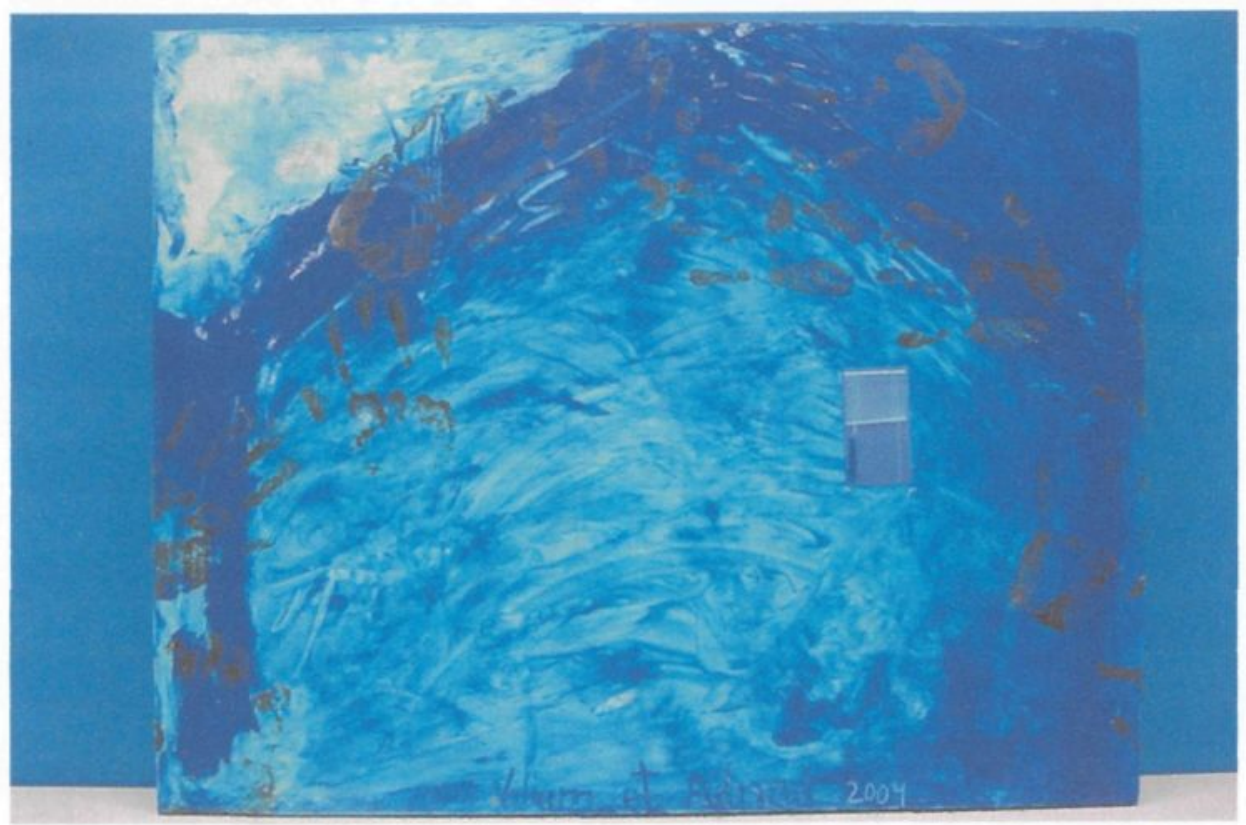

La maison, 2004, acrylique, papier, médium acrylique translucide semi-brillant

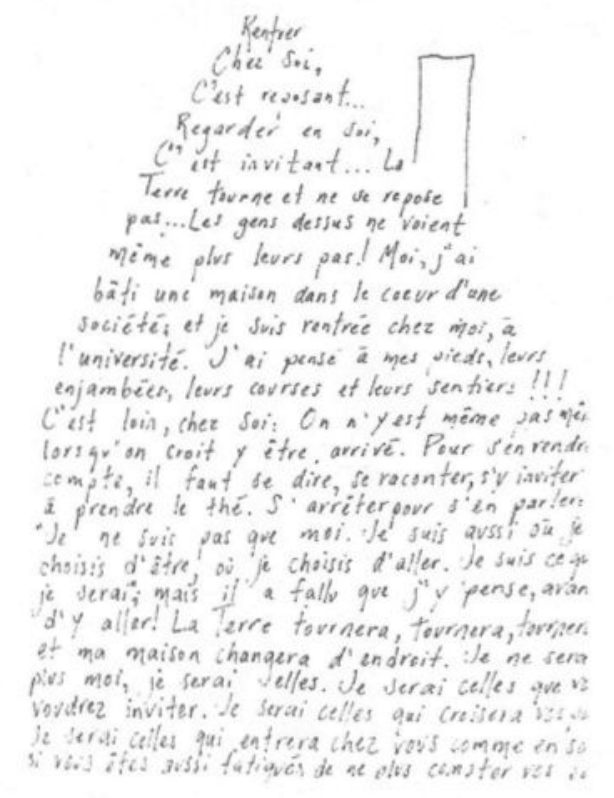

Poème composé par Valérie suite à l'expérience, un extrait de ce poème est récité dans la trame sonore, phase finale de l'œuvre de ma recherche de maîtrise. 


\section{David}

À la demande de mon ami, nous planifions notre rencontre après le coucher du soleil. La lune n'était pas pleine, comme il l'aurait souhaité, et pourtant bien à sa demie, elle brillait fièrement dans le firmament. David étant un passionné de plein air, c'était très probable que nous allions peindre dehors. Comme matériau, je lui propose un grand morceau de toile non tendu. Suite à l'expérience de construction du cadre avec Valérie, je jugeai cette méthode non-concluante, j'ai donc dû adapter les matériaux à la personne et à l'expérience. De toute évidence, cette rencontre nécessitait des éléments facilement transportables. Je choisis comme point $\mathrm{A}$ le pt $\mathrm{B}$ de Valérie ce qui m'amènera a faire un lien entre les expériences. La session est presque terminée, il n'y a pas un chat dans l'université, il est $22 \mathrm{~h}$. David, confiant, propose que l'on prenne place sur le banc adjacent aux fenêtres du centre social. On reste assis un instant, tout à coup, il clame qu'il a une nouvelle idée comme point B. Tout content de sa trouvaille, il est convaincu que son illumination est une bien meilleure idée que celle qu'il avait en tête. On se lève donc vers ce lieu choisi. Nous montons le grand escalier, en se dirigeant vers la sortie principale, porte est. Le lieu est calme, nos pas réguliers, il y a une intensité du moment, la session s'achève, les images mémorisées ont l'image d'un rite de passage, un cycle qui se termine, l'achèvement d'une étape. L'air est frais. Arrivés sur le site, se trouve une grosse pierre qui nous servira de chevalet. On s'inspirera des éléments géographiques, des ombres et de la nature qui nous entourent pour façonner l'œuvre. Des envolées d'oies blanches passaient au-dessus de nous, c'était vraiment une soirée où plusieurs phénomènes naturels se sont mis à contribution. Sur la toile, nous avons tracé nos deux silhouettes à l'aide d'un pastel à l'huile, les deux silhouettes s'imbriquent l'une dans l'autre pour former un personnage ailé dont une jambe devient un arbre aux racines découvertes, tandis que l'autre jambe est celle d'un oiseau palmipède. L'inspiration du chevalet, la pierre, a donné naissance à un frottis fait avec de la terre prélevée sur place, qui représente un genre de montagne volcan. En bas à gauche, l'évocation de la ville avec des petits lampadaires orange tracés à la craie.

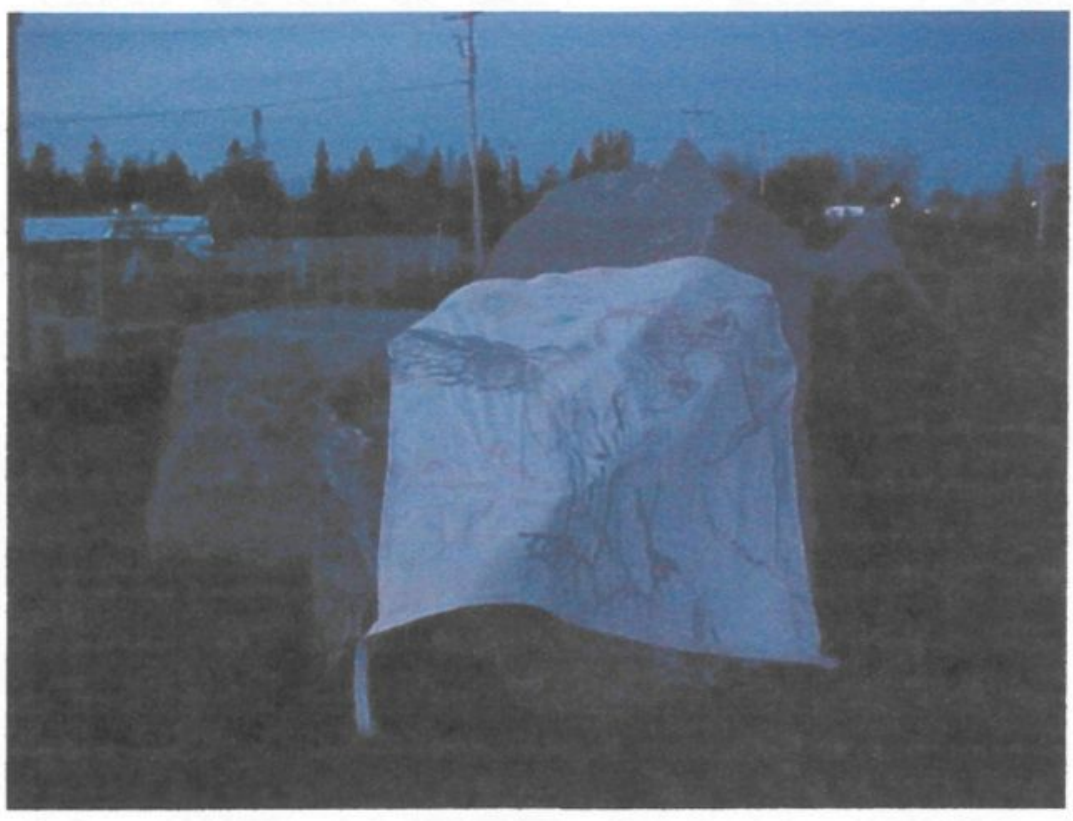

Phoenix, 2004, pastel huile, terre 


\section{Nadia moi-même}

Début de soirée, il fait encore clair, c'est l'été. Je me dis qu'avec tout ce que j'ai réalisé sur moi et les intentions de mes actions artistiques, il serait intéressant de faire cette expérience pour moimême accompagnée de moi-même. Je choisis donc le pt $\mathrm{B}$ de David comme mon point de départ. Depuis, la pelouse est longue, le soleil est encore chaud, je prends place en dessous des roches qui forment une mini caverne, qui offre un abris d'ombre. Je prends le temps d'arriver, de me familiariser avec le lieu, de m'imprégner du lieu. J'initie le pas en direction du point B que j'avais choisi comme point d'arrivée. Je traverse donc le terrain adjacent au Pavillon de la Recherche Forestière, où des enfants de 4 ans jouaient un match de soccer, devant des parents rassemblés le long du terrain, assis dans leur chaise pliante. D'autres enfants s'amusaient au loin avec un filet non utilisé. Je m'arrête pour regarder la joute quelques instants, les joueurs sont nonchalants, était-ce dû à la chaleur, au manque de concentration ou tout simplement à un désintéressement du jeu? Tandis que je continuais ma route, le frère d'un joueur s'était pris le pied dans un filet, c'était drôle de voir la mère découragée de son fils qui s'était pris le pied dans le but. Je traverse la rue qui mène à l'université pour me retrouver dans une plantation de mélèzes, depuis ces deux ans que je fréquente cette institution je n'avais jamais remarqué ces arbres magnifiques qui, à deux pas du Pavillon des Arts, grandissent. Je suis émerveillée par ce vert tendre qu'offre ces branches garnies de délicates épines. Au loin, je vois le grand érable argenté qui est mon point d'arrivée. Je traverse un fossé fraîchement creusé, c'est qu'ils font des réaménagements autour de l'UQAC depuis la construction du nouveau Pavillon de l'Aluminium. Une route accessible aux voitures passera par ici vu la largeur du fossé. Rendue à l'arbre, je profite de l'ombre et regarde autour de moi, la végétation, les voitures au loin qui passent, les motocyclettes, les insectes. Je n'apporte aucun matériel pour faire l'œuvre trace, comptant sur ce que je trouverai sur place. Je décide d'utiliser de ce contenu de ma vessie en aspergeant de ce contenue translucide, l'herbe près d'une d'épinette. $\mathrm{Ce}$ geste du quotidien essentiel et très simple devint l'œuvre et la trace. J'ai pensé aux animaux qui usent de ce liquide afin de marquer le territoire, de délimiter un lieu. Ce geste de ma part revient à l'acte intime dans un endroit public, le soulagement d'un besoin naturel dans la nature, quoique cette nature fasse partie d'un site conféré à une institution, soit l'université. Cette dernière expérience marque la clôture d'une série d'expériences qu'il m'a été donné d'explorer lors de ma recherche de maîtrise en art.

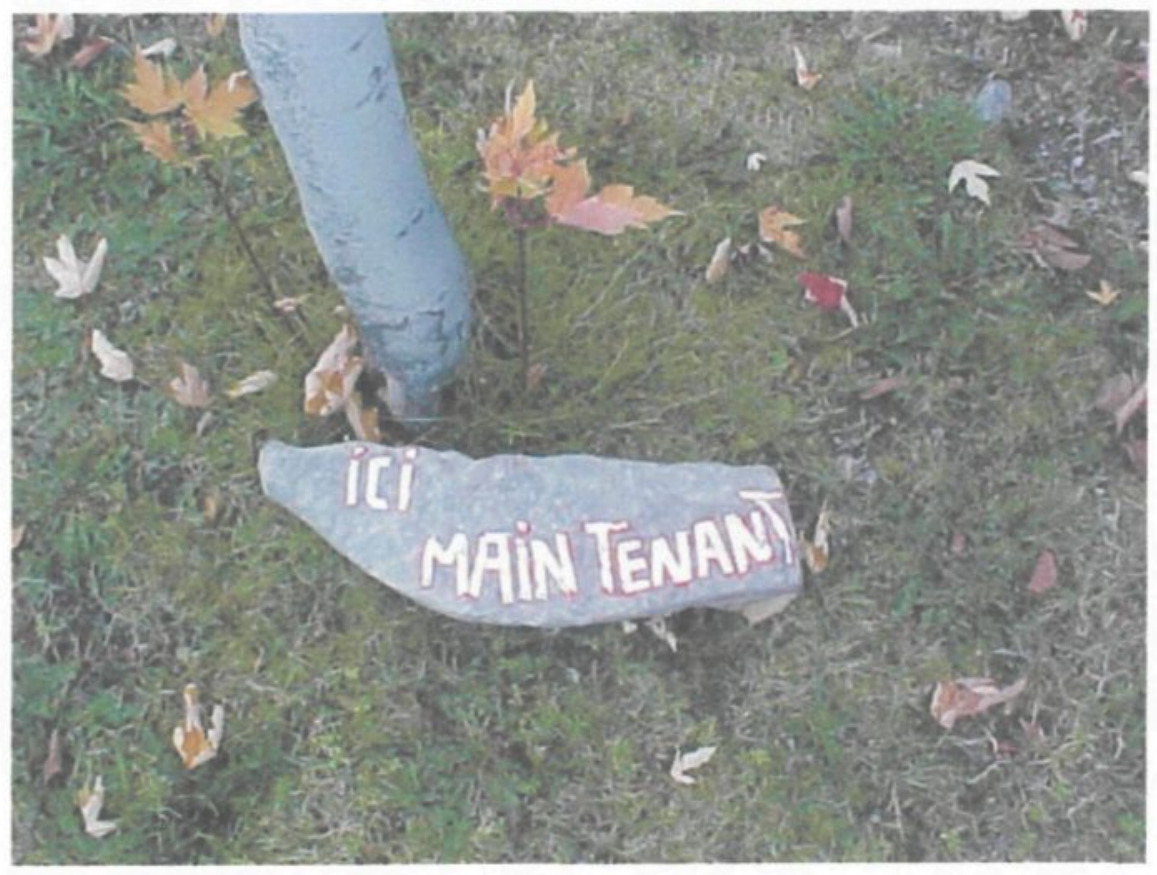




\section{Bibliographie}

BERTRAND, Pierre (2001), L'art et la vie, Montréal, Liber, 128 p.

BERTRAND, Pierre (2000), L'éloge de la fragilité, Montréal, Liber, $260 \mathrm{p}$.

BOURRIAUD, Nicolas (2001), L'esthétique Relationnelle, Presse du réel, 118 p.

COMPTE-SPONVILLE, André (2001), Dictionnaire philosopique, Paris. Presses

Universitaires de France, 646 p.

DUCHAMP, Marcel (1994) Entretiens avec Macel Duchamp, Marseille, A, Dimanche GAUTHIER, Arnold (1996) Le Tuyau, Cantz, Ces gens ordinaires, $86 \mathrm{p}$.

HEGEL, G.W.F (1993), Esthétique des arts plastiques, des sciences et des arts, Paris, 332p.

KAPROW, Allan (1996) L'art et la vie confondus, Paris, Centre Pompidou, $280 \mathrm{p}$.

LOUBIER, Patrice et NINACS, AnneMarie (2001), Les commensaux quand l'art se fait circonstances, Montréal, Skol, 243 p.

MALRAUX, André (1926), La tentation de l'occident, Paris, Bernard Grasset, 217 p.

MAFFESSOLI, Michel (1992), La transfiguration du politique, Paris, Grasset, 307 p.

MAFFESSOLI, Michel (1993) La comtemplation du monde, Paris, Grasset, 235 p.

MULLE, Eugène (1997) Ma Vie, Ma Vigne, St-Catherine, Quatre-vents, 69 p.

TAPIES, Antoni (1974) La pratique de l'art, Paris, Gallimard, 284 p.

TODD, Olivier (2001) Une vie, Paris, Gallimard, 984 p.

\section{Articles}

COTTON, Sylvie (2003), Les pratiques artistiques citoyenness processus politique?, p. 4246, Esse : Arts et Opinions, no.48, Citoyen Volontaire, Printemps été 2003, Montréal, Esse 
JACOB, Louis (2003), Citoyen à l'oeuvre, p 20-25, Esse : Arts et Opinions, no.48, Ciroyen Volontaire, Printemps été 2003, Montréal, Esse, 77p.

NEUMARK, Devora (2003) Entre-nous, p42-46, Esse : Arts et Opinions, no.48, Citoyen Volontaire, Printemps été 2003, Montréal, Esse, 77 p.

KAZMIERCZAK, Wladyslaw (2000), À propos de la performance des années quatrevingt-dix, p 34-37, Inter, no.74, Québec, Éditions intervention.

LACHANCE, Michaël (2001), L'art performance : une fièvre de la rencontre, Spirale, novembre-décembre 2001, Montréal

Dictionnaire de la langue française, Encyclopédie et Noms propres, (1988) Paris, Hachette, $1407 \mathrm{p}$ 


\section{Lectures stimulatives}

ARDENNE, Paul (1999), Lart dans son moment politique, Belgique, La lettre volée, 416 p. BEAUVOIR, Simone (1954), L'Amérique au jour le jour, Paris, Gallimard, 345 p.

BELLAVANCE, Guy (2000), Monde et réseau de l'art, Montréal, Liber, 307 p.

BERTRAND, Pierre (2001), L'art et la vie, Montréal, Liber, 128 .p.

BERTRAND, Pierre (2000), L'éloge de la fragilité, Montréal, Liber, $260 \mathrm{p}$.

BEUYS, Joseph (1988), Par la présente je n'appartiens plus à l'art, Paris, L'arche, 161 p.

BRADLEY, Jessica et JOHNTON, Lesley (1998), Réfractions, Trajets de l'art contemporain au Canada, Montréal, Artexte, La lettre volee, 486 p.

BOURRIAUD, Nicolas (2001), L'esthétique Relationnelle, Presse du réel, 118 p.

BROOK, Peter (1977), L'espace vide, Paris. Édition du seuil, 181 p.

CASTARÈDE, Marie-France(1989) La voix et ses sortilèges, Paris, Les belles lettres, 263p.

CYRULNIK, Boris (2000), Les nourritures afffectives, Paris, Odile Jacob, 244 p.

CYRULNIK, Boris (1993), Un merveilleux malheur, Paris, Odile Jacob

CYRULNIK, Boris (1995), La naissance du sens, Paris, Hachette, 167 p.

DÜRCKHEIM, Graf Karlfried (1987), L'expérience de la transcendance, France, Sagesse du corps, $157 \mathrm{p}$.

FRASER, Marie (2001), Le ludique, Québec, Caractéra, 159 p.

GLEIZAL, Jean-Jaques (1994), L'art et le politique, France, Presse universitaire de France, $257 \mathrm{p}$.

HEGEL, G.W.F (1993), Esthétique des arts plastiques, des sciences et des arts, Paris, 332p.

LACHANCE' Michaël (2001), Les penseurs de fer, Canada, trait d'union, 212 p.

LACY Suzanne (1995), Mapping the terrain new gender of art, Seattle, Bay press $291 \mathrm{p}$. 
MALRAUX, André (1926), La tentation de l'occident, paris, Bernard Grasset, $217 \mathrm{p}$.

MAFFESSOLI, Michel (1992), La transfiguration du politique, Paris, Grasset, 307 p.

MARTEL, Richard (1998), Art Action 1958-1998, Canada, intervention, 496 p.

RICHARD, Alain-Martin et ROBERTSON, Clive (1991). Performance au -in Canada 1970-1990, Canada, inter éditeur, 395 p.

SIGNEL, Karen (1992), La sagesse du cour, Montréal, Le jour éditeur, 360 p.

ST-ARNAUD, Yves, (1989), Les petits groupes participation et communication, Canada, Gaetan Morin, 177 p.

\section{Articles}

COTTON, Sylvie (2003), Les pratiques artistiques citoyenness processus politique?, p. 4246, Esse : Arts et Opinions, no.48, Citoyen Volontaire, Printemps été 2003, Montréal, Esse, $77 \mathrm{p}$.

JACOB, Louis (2003), Citoyen à l'oeuvre, p 20-25, Esse : Arts et Opinions, no.48, Citoyen Volontaire, Printemps été 2003, Montréal, Esse, 77p.

NEUMARK, Devora (2003) Entre-nous, p42-46, Esse : Arts et Opinions, no.48, Citoyen Volontaire, Printemps été 2003, Montréal, Esse, 77 p.

KAZMIERCZAK, Wladyslaw (2000), À propos de la performance des années quatrevingt-dix, p 34-37, Inter, no.74, Québec, Éditions intervention.

LACHANCE, Michaël (2001), L'art performance : une fièvre de la rencantre, Spirale, novembre-décembre 2001, Montréal 